\title{
Post-Irradiation-Examination of the ORNL and LANL Samples
}

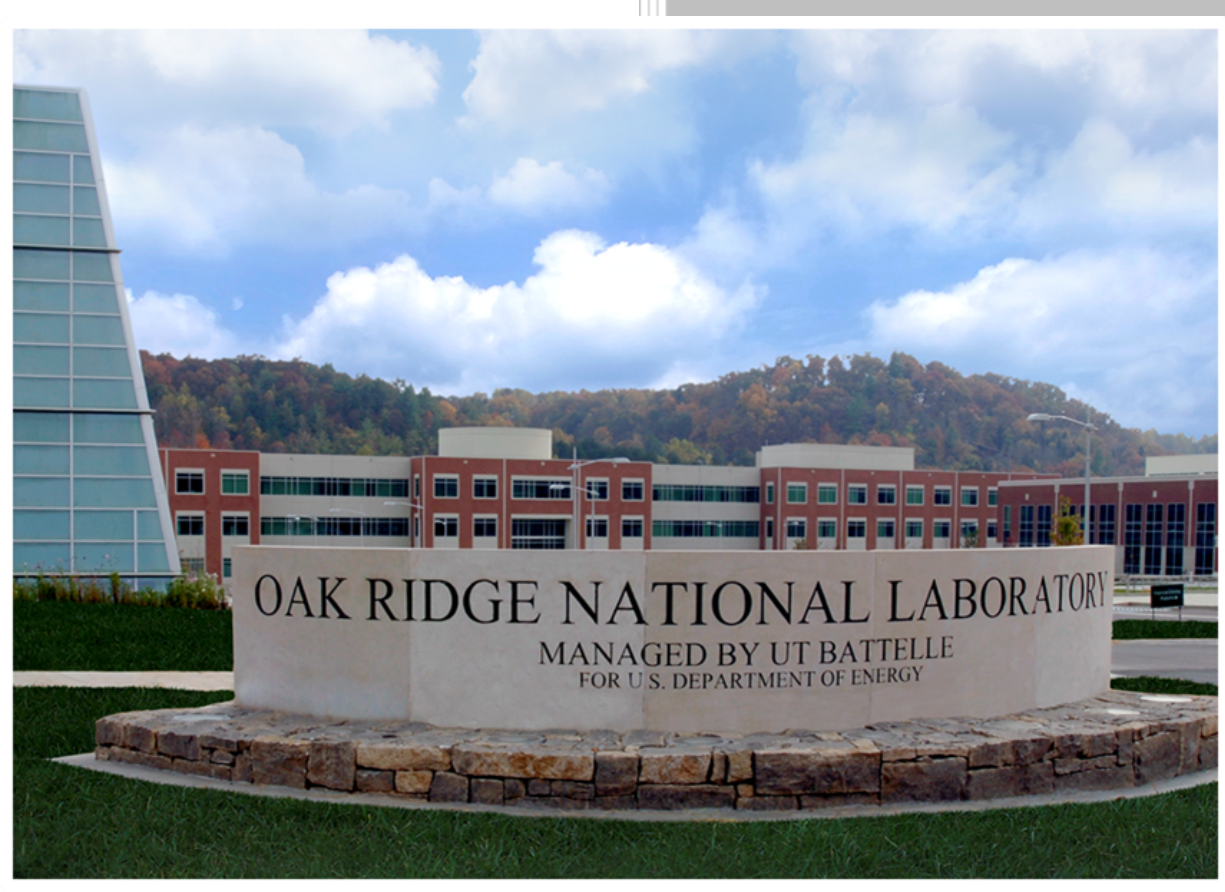

Approved for public release.

Distribution is unlimited.

Weicheng Zhong

Lizhen Tan

Kory Linton

Oak Ridge National Laboratory

Tarik A. Saleh

Los Alamos National Laboratory

December 20, 2019 


\section{DOCUMENT AVAILABILITY}

Reports produced after January 1, 1996, are generally available free via US Department of Energy (DOE) SciTech Connect.

Website www.osti.gov

Reports produced before January 1, 1996, may be purchased by members of the public from the following source:

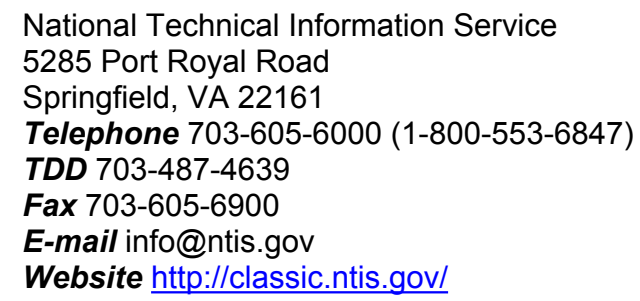

Reports are available to DOE employees, DOE contractors, Energy Technology Data Exchange representatives, and International Nuclear Information System representatives from the following source:

Office of Scientific and Technical Information

PO Box 62

Oak Ridge, TN 37831

Telephone 865-576-8401

Fax 865-576-5728

E-mail reports@osti.gov

Website http://www.osti.gov/contact.html

This report was prepared as an account of work sponsored by an agency of the United States Government. Neither the United States Government nor any agency thereof, nor any of their employees, makes any warranty, express or implied, or assumes any legal liability or responsibility for the accuracy, completeness, or usefulness of any information, apparatus, product, or process disclosed, or represents that its use would not infringe privately owned rights. Reference herein to any specific commercial product, process, or service by trade name, trademark, manufacturer, or otherwise, does not necessarily constitute or imply its endorsement, recommendation, or favoring by the United States Government or any agency thereof. The views and opinions of authors expressed herein do not necessarily state or reflect those of the United States Government or any agency thereof. 
ORNL/TM-2019/1432

M3NA-17OR0204019

FY 2017 Consolidated Innovative Nuclear Research (CINR)

Nuclear Science User Facilities (NSUF)

Light Water Reactor Sustainability (LWRS)

POST-IRRADIATION EXAMINATION OF THE ORNL and LANL SAMPLES

\author{
Weicheng Zhong, Lizhen Tan, and Kory Linton \\ Oak Ridge National Laboratory \\ Tarik Saleh \\ Los Alamos National Laboratory
}

Date Published: December 20, 2019

Prepared by

OAK RIDGE NATIONAL LABORATORY

Oak Ridge, TN 37831-6283

managed by

UT-BATTELLE, LLC

for the

US DEPARTMENT OF ENERGY

under contract DE-AC05-00OR22725 



\section{CONTENTS}

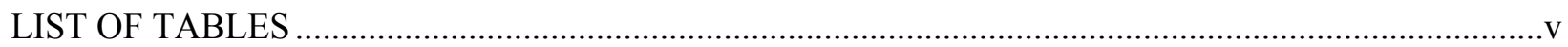

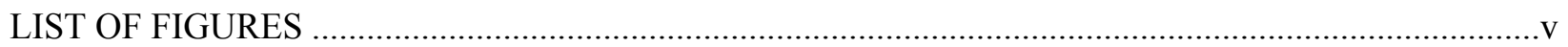

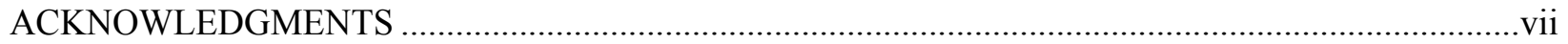

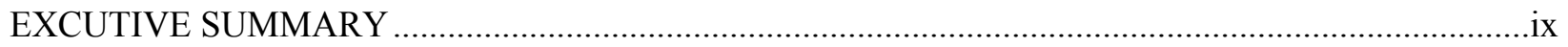

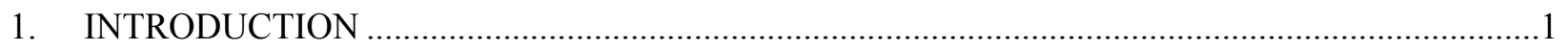

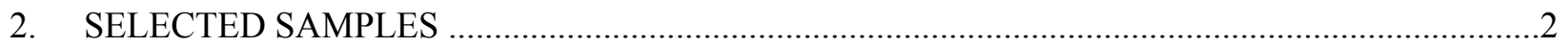

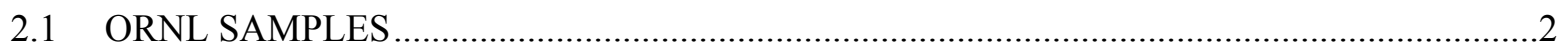

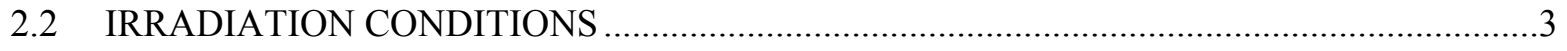

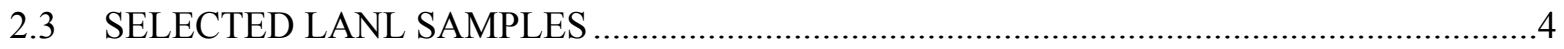

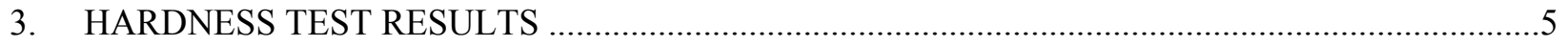

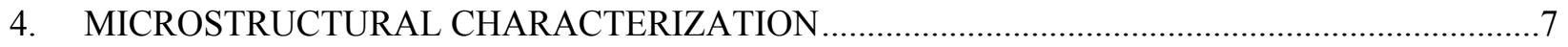

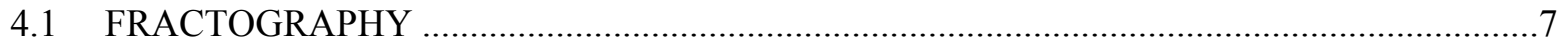

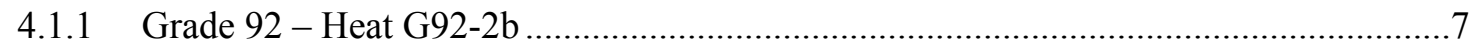

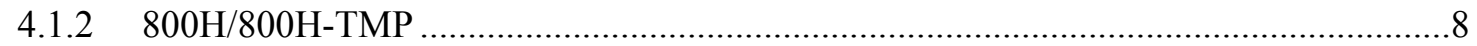

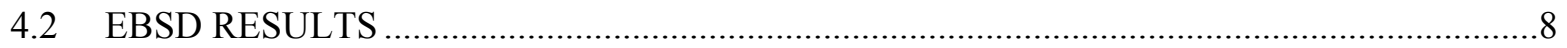

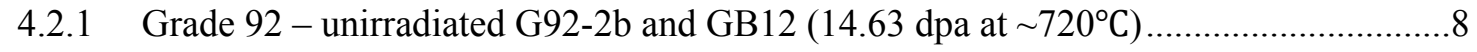

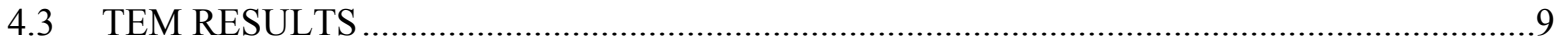

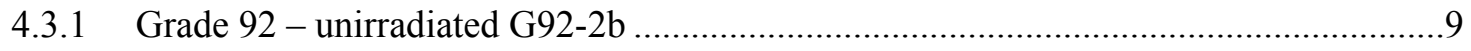

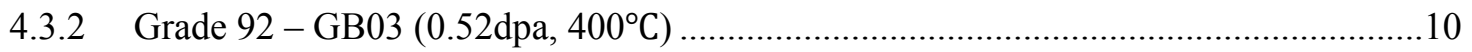

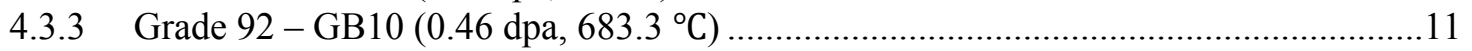

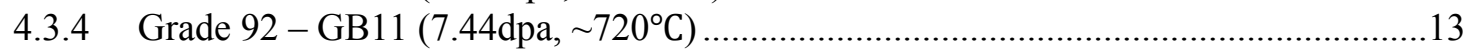

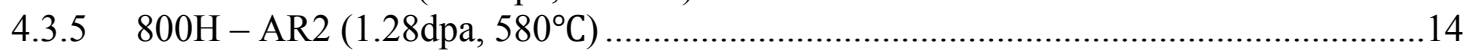

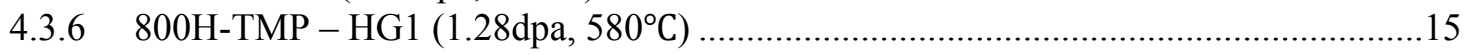

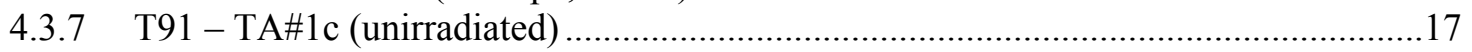

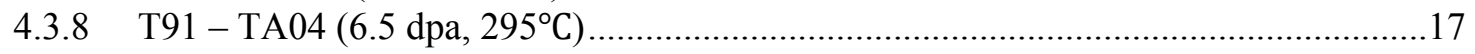

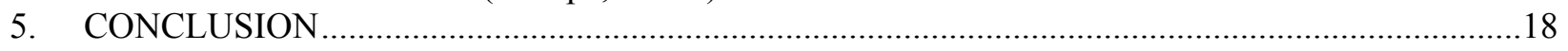

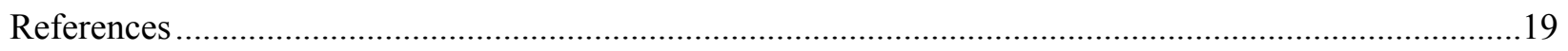




\section{LIST OF TABLES}

Table 1. Irradiation condition of ORNL HFIR-irradiated samples......................................................2

Table 2. Compositions in weight percent (wt\%) of the HFIR samples, with Fe as balance........................2

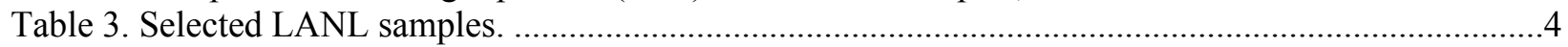

Table 4. Composition in weight percent (wt \%) of the LANL samples, with Fe as balance........................4

\section{LIST OF FIGURES}

Figure 1. Irradiation temperature as a function of dose of steel samples irradiated with the G92-2b samples.

Figure 2. Irradiation temperature and dose conditions of the ORNL samples. .......................................4

Figure 3. Vickers hardness of (a) G92-2b (GB03-GB12) and T91 (TA04) and (b) 800H (AR2) and $800 \mathrm{H}-\mathrm{TMP}$ (HG1).

Figure 4. Dose dependence of G92-2b at high and low irradiation temperature. ......................................6

Figure 5. Fractography of the tensile tested (a, d) GB03, (b, e) GB10, (c, f) GB11 samples......................7

Figure 6. Fractography of the tensile tested $(a, b, c)$ AR2 and (d, e, f) HG1 samples................................

Figure 7. EBSD results of $(a, b)$ archived unirradiated G92-2b and $(c, d)$ GB12 ....................................

Figure 8. STEM bright field images (a, c, d) and TEM dark field image (b) of the unirradiated G92-2b showing a) $\mathrm{M}_{23} \mathrm{C}_{6}$ precipitates, b) MX precipitates, c) NbN precipitates, and d) dislocations.

Figure 9. STEM (a, b, c, d, f) bright field images, and (e) TEM dark field image of GB03 at the tab section.

Figure 10. STEM $(a, b)$ bright field images and (c) the diffraction patterns of the twin in (b) of GB03 at the gauge section.

Figure 11. STEM bright field images (a, b, c, d, f) and TEM bright field image (e) of GB10 at the tab section, showing (a) overview, (b) dislocation, (c, d) $\mathrm{M}_{23} \mathrm{C}_{6}$ precipitates, (e) Laves Phase precipitate, and (f) V-rich precipitates pointed by the orange arrows.

Figure 12. STEM $(a, f)$ bright field images and (b, d, e) TEM bright field images and (e) the FFT of the $\mathrm{NbN}$ precipitate of GB10 at the gauge section.

Figure 13. STEM (a, b, c) bright field images, and (d) Nb maps near voids of GB11 at the tab section.

Figure 14. STEM bright field image GB11 at the gauge section.

Figure 15. STEM $(a, b)$ bright field images and $(c, d)$ diffraction patterns at the tab section. .....................14

Figure 16. STEM $(a, b)$ bright field images and $(c)$ dark field image on the dislocation loops. ..................15

Figure 17. STEM $(a, b)$ bright field images and $(c, d)$ high resolution TEM image with FFT as the inset, and (e, f) dark fielding images of HG1 at the tab section...................................................16

Figure 18. STEM (a) bright field image and (b) diffraction pattern under [001] zone and (c) dark field image of $\gamma$ ' precipitates of HG1 at the gauge section.........................................................16

Figure 19. STEM (a, c) bright field image and (b) dark field image of MX precipitates of TA\#1c. ..........17

Figure 20. STEM bright field images showing ( $a, b) \mathrm{M}_{23} \mathrm{C}_{6}$ precipitates and (c) dislocation loops at TA04. 


\section{ACKNOWLEDGMENTS}

This research was sponsored by the U.S. Department of Energy (DOE), Office of Nuclear Energy (NE), the FY 2017 Consolidated Innovative Nuclear Research (CINR) Nuclear Science User Facilities (NSUF) program and the Light Water Reactor Sustainability (LWRS) program. We gratefully acknowledge the support provided by Alison Hahn of DOE-NE and Rory Kennedy of Idaho National Laboratory for the NSUF access support and Tom Rosseel and Xiang Chen of Oak Ridge National Laboratory (ORNL) for the research and development support of this project.

The authors are grateful to Kory Linton and Kurt Terrani of ORNL for providing essential support on the access to the LAMDA facilities through the NSUF program and Patricia Tedder, Stephanie Curlin, Brandon Hambrick and Joshua Schmidlin of ORNL for sample reception, preparation, and hardness measurements. Xiang Chen and Daniel Morrall of ORNL are appreciated for technical review of this report. 


\section{EXCUTIVE SUMMARY}

Ferritic-martensitic steel G92-2b (an optimized Grade 92 heat) and austenitic stainless steel $800 \mathrm{H}$ and its Grain Boundary Engineering (GBE)-treated version 800H-TMP (ThermoMechanical Processing) were irradiated in the HFIR. Ferritic-martensitic steel T91 was irradiated in the ATR. Selected G92-2b samples were irradiated up to $14.66 \mathrm{dpa}$ at two temperature ranges: $400-496.7^{\circ} \mathrm{C}$ and $683.3-720^{\circ} \mathrm{C}$. Selected $800 \mathrm{H}$ and $800 \mathrm{H}-\mathrm{TMP}$ samples were irradiated to $1.28 \mathrm{dpa}$ at $580^{\circ} \mathrm{C}$. A selected T91 sample was irradiated to $6.5 \mathrm{dpa}$ at $295^{\circ} \mathrm{C}$. Vickers hardness measurements, fractography, and microstructural characterization were performed on the selected samples in LAMDA.

Hardening of G92-2b was observed only at the lower doses and lower irradiation temperatures (400$\left.496.7^{\circ} \mathrm{C}\right)$, with GB03 $\left(0.52 \mathrm{dpa}\right.$ at $\left.400^{\circ} \mathrm{C}\right)$ and GB04 $\left(7.44 \mathrm{dpa}\right.$ at $\left.\sim 460^{\circ} \mathrm{C}\right)$ showing $\sim 12 \%$ and $\sim 8 \%$ hardening, respectively. Softening by $\sim 14 \%$ was observed for GB05 $\left(14.66 \mathrm{dpa}\right.$ at $\left.496.7^{\circ} \mathrm{C}\right)$ due to the longer irradiation time at $496.7^{\circ} \mathrm{C}$. Softening of $\mathrm{G} 92-2 \mathrm{~b}$ was more prevalent at the higher irradiation temperatures $\left(683.3-720^{\circ} \mathrm{C}\right)$, with GB10 $\left(0.46 \mathrm{dpa}\right.$ at $\left.683.3^{\circ} \mathrm{C}\right)$, GB11 $\left(7.44 \mathrm{dpa}\right.$ at $\left.\sim 720^{\circ} \mathrm{C}\right)$, and $\mathrm{GB} 12$ (14.63 dpa at $\sim 720^{\circ} \mathrm{C}$ ) showing $\sim 8 \%, \sim 8 \%$, and $\sim 40 \%$ softening, respectively. Samples AR2 (800H) and HG1 (800H-TMP) showed increased hardness after irradiation to $1.28 \mathrm{dpa}$ at $580^{\circ} \mathrm{C}$. The irradiated T91 (TA04) showed $\sim 65 \%$ hardness increase, as compared to that of unirradiated T91 from the published literature.

The fractography results of GB03 $\left(0.52 \mathrm{dpa}\right.$ at $\left.400^{\circ} \mathrm{C}\right)$, GB10 $\left(0.46 \mathrm{dpa}\right.$ at $\left.683.3^{\circ} \mathrm{C}\right)$, and GB11 $(7.44 \mathrm{dpa}$ at $\sim 720^{\circ} \mathrm{C}$ ), together with the previously completed fractography of GB04 (7.44 dpa at $\left.\sim 490^{\circ} \mathrm{C}\right)$, GB05 $\left(14.66 \mathrm{dpa}\right.$ at $\left.496.7^{\circ} \mathrm{C}\right)$, and $\mathrm{GB} 12\left(14.63 \mathrm{dpa}\right.$ at $\left.\sim 720^{\circ} \mathrm{C}\right)$, indicated that the ductility of G92-2b was maintained up to $14.66 \mathrm{dpa}$ at the lower irradiation temperatures of $400-496.7^{\circ} \mathrm{C}$, while some loss of ductility (less necking) was observed for higher doses at the higher irradiation temperatures of 683.3$720^{\circ} \mathrm{C}$. This agrees with the previously reported tensile test results of G92-2b, where the elongation of G92-2b was reduced at higher doses at the higher irradiation temperatures. Dimple sizes increased at higher doses, which are more evident at the higher irradiation temperatures of $683.3-\sim 720^{\circ} \mathrm{C}$. Fractography of $800 \mathrm{H}$ and $800 \mathrm{H}$-TMP suggests that both samples failed in a brittle mode by intergranular fracture with negligible necking.

Electron backscatter diffraction characterization of GB12 $\left(14.63\right.$ dpa at $\left.\sim 720^{\circ} \mathrm{C}\right)$ indicated the recovery of lath structure, which was generally replaced by an equiaxed grain structure. Transmission electron microscopy characterization showed the presence of $\mathrm{M}_{23} \mathrm{C}_{6}(\mathrm{M}=$ primarily $\mathrm{Cr}), \mathrm{MX}(\mathrm{M}=$ primarily $\mathrm{V})$, spherical $\mathrm{Nb}(\mathrm{C}, \mathrm{N})$ precipitates, and Laves phase precipitates in the G92-2b samples. MX precipitates with sizes of 20-30 nm were observed at boundaries of smaller grains, indicating the pinning effect of V-rich precipitates. Lath structure recovery was more evident at the higher irradiation temperatures (683.3$\sim 720^{\circ} \mathrm{C}$ ). The densities of line dislocations and of $\mathrm{M}_{23} \mathrm{C}_{6}$ precipitates decreased after irradiation. The irradiated T91 (TA04) showed the growth of $\mathrm{M}_{23} \mathrm{C}_{6}$ precipitates $101 \pm 40 \mathrm{~nm}$ from the initial $68 \pm 22 \mathrm{~nm}$ in the unirradiated condition. Dislocation loops of both $\{100\}$ and $\{111\}$ types were present in TA04, which were not pronounced in the G92-2b samples irradiated above $400^{\circ} \mathrm{C}$. Microstructural characterization of AR2 $(800 \mathrm{H})$ showed accumulation of large $\mathrm{M}_{23} \mathrm{C}_{6}$ precipitates at grain boundaries. Smaller $\mathrm{M}_{23} \mathrm{C}_{6}$ precipitates inside grains showed the cube-on-cube orientation relationship with the matrix. Accumulation of large $\mathrm{M}_{23} \mathrm{C}_{6}$ and TiC precipitates was observed at grain boundaries in HG1 (800H-TMP). Fine $\mathrm{M}_{23} \mathrm{C}_{6}$ and $\mathrm{TiC}$ precipitates were also present inside grains with TiC often embedded in the $\mathrm{M}_{23} \mathrm{C}_{6}$ precipitates. $\gamma^{\prime}$ precipitates were observed inside grains, which have a cube-on-cube orientation relationship with the matrix. 
Further systematic data analyses, together with some complementary experiments, will be pursued for these samples to foster peer-reviewed journal article publications. 


\section{INTRODUCTION}

Advanced alloys are desired to provide greater safety margins, design flexibility and economics compared to traditional reactor materials. Ferritic-martensitic steel Grade 92 and austenitic Alloy 800/800H are two of the promising alloys of interest by the current Advanced Radiation-Resistant Materials (ARRM) and Light Water Reactor Sustainability (LWRS) programs. However, systematic studies on neutronirradiation induced changes in microstructures and mechanical properties are deficient for the alloys. The objective of this project is to develop correlations between microstructures and mechanical properties of the neutron-irradiated Grade 92 and Alloy $800 / 800 \mathrm{H}$, based on the experimental results generated from this work. It is expected to develop broader correlations for these types of steels by comparing the results of this work with that of similar alloys such as Grade 91, Alloy 709 and type 304/316 stainless steels from literature and the ongoing studies, with the aid of thermodynamics, kinetics, and microstructural hardening modeling.

Samples of Grade 92 and Alloy $800 \mathrm{H}$ selected in this work were primarily irradiated in two test reactors for up to $\sim 14$ displacements per atom (dpa) at $\sim 241-720^{\circ} \mathrm{C}$. Samples of Grade 91, irradiated in the same reactors, were selected as references of Grade 92. Few samples from other two reactors will be included for comparison. Both irradiated and unirradiated samples from the same heat of the materials will be examined to elucidate the radiation-induced evolutions in microstructures, mechanical properties, and deformation mechanisms. To be more specific, mechanical properties such as tensile properties, modulus, hardness, and viscoplasticity will be measured through tensile, Vickers hardness and nanoindentation tests. Microstructural characterization of the samples will be carried out using the state-of-the-art instruments and techniques provided through the Nuclear Science User Facilities (NSUF). The obtained experimental results will then be used to establish the knowledgebase on the effects of alloy chemistry, thermomechanical-processing, and irradiation conditions on microstructures and mechanical properties of Grade 92 and Alloy 800H.

Outcomes of this project will include a comprehensive set of data including microstructures and mechanical properties of both irradiated and unirradiated samples of the interested steels, which will not only help understanding the essential performance of similar alloys, but more importantly to gain indispensable insights into the development of advanced alloys with superior radiation resistance. The outcomes can also serve as inputs and/or benchmarks for microstructural and mechanical property modeling of irradiated ferritic-martensitic and austenitic steels. The accomplishment of this project will directly benefit the LWRS program and bring values to the Advanced Reactor Technologies and Small Modular Reactors programs.

Samples irradiated in the High Flux Isotope Reactor (HFIR) of Oak Ridge National Laboratory (ORNL) have been tensile tested, and the result have been reported [1] [2]. Hardness measurement and the microstructure characterization have been performed on the samples. In addition, selected Los Alamos National Laboratory (LANL) samples have been irradiated in the Advanced Test Reactor (ATR) of Idaho National Laboratory (INL), and microstructure characterization has been performed on the samples. This report summarizes the post-irradiation examination results of the ORNL samples and LANL samples. 


\section{SELECTED SAMPLES}

\subsection{ORNL SAMPLES}

The selected ORNL samples include G92-2b and 800H samples irradiated to $0.46-14.66$ dpa at 400 to $\sim 720^{\circ} \mathrm{C}$ in the High Flux Isotope Reactor (HFIR) of ORNL, which are listed in Table 1, together with the alloy compositions in

Table 2. The G92-2b is a heat of optimized Grade 92, which was developed under the Advanced Reactor Technologies (ART) program [3]. It showed improved strength and creep resistance compared with conventional Grade 92 such as NF616. The AR2 and HG1 samples are Incoloy $800 \mathrm{H}$ samples in a commercial solution-annealed condition and a thermomechanical processing (TMP) condition, respectively. The G92-2b samples are type SS-J2 miniature tensile specimens with $16 \times 4 \times 0.51 \mathrm{~mm}$ overall size and $5 \times 1.2 \times 0.51 \mathrm{~mm}$ for the gauge section. The $800 \mathrm{H}$ and $800 \mathrm{H}-\mathrm{TMP}$ samples are in type SS-3 miniature tensile specimens with $25.4 \times 4.95 \times 0.76 \mathrm{~mm}$ overall size and $7.62 \times 1.52 \times 0.76 \mathrm{~mm}$ for the gauge section.

G92-2b was normalized at $1080^{\circ} \mathrm{C}$ for $1 \mathrm{~h}$, followed by hot-rolling to $0.6^{\prime}$ "-thick plate from 1 " at $1080^{\circ} \mathrm{C}$ and water quenched, and tempered at $750^{\circ} \mathrm{C}$ for $2 \mathrm{~h}$ with air cooling. The $800 \mathrm{H}$ was solution-annealed at $1177^{\circ} \mathrm{C}$ for 24 minutes per centimeter of thickness, followed by a water quench. The $800 \mathrm{H}-\mathrm{TMP}$ was based on the $800 \mathrm{H}$, subjected to $\sim 6.6 \%$ thickness reduction by rolling at room temperature and then annealed at $1050^{\circ} \mathrm{C}$ for $1.5 \mathrm{~h}$ with water quench. The TMP led to a grain boundary engineering (GBE) effect to significantly increase the fraction of low- $\Sigma$ coincidence site lattice (CSL) boundaries, e.g., nearly $70 \%$ (800H-TMP) vs. $\sim 40 \%(800 \mathrm{H})$ low- $\Sigma$ CSL boundaries [4]. GBE with a significantly increased fraction of low- $\Sigma$ CSL boundaries would benefit a variety of properties such as strength and resistance to creep, stress corrosion cracking, and oxidation [5]. The 800H-TMP exhibited noticeable enhancements in the resistance to thermal aging [6] and corrosion in supercritical water and high-temperature air [7] [8] [9] [10]. Preliminary studies also showed some improvements in resistance to neutron irradiation [11] [12]. Therefore, the pair of $800 \mathrm{H} / 800 \mathrm{H}-\mathrm{TMP}$ samples were irradiated in a nearly identical condition to elucidate the beneficial effects of GBE/TMP on the neutron irradiation resistance of $800 \mathrm{H}$.

Table 1. Irradiation condition of ORNL HFIR-irradiated samples.

\begin{tabular}{|c|c|c|c|c|c|}
\hline Specimen type & Alloy & Sample ID & Temperature $\left({ }^{\circ} \mathrm{C}\right)$ & Dose (dpa) & Irradiation time (days) \\
\hline \multirow{4}{*}{ SS-J2 } & & GB03 & 400 & 0.52 & 10 \\
\cline { 3 - 6 } & \multirow{3}{*}{ G92-2b } & GB04 & $\sim 490$ & 7.44 & 126 \\
\cline { 3 - 6 } & & GB05 & 496.7 & 14.66 & 228 \\
\cline { 3 - 6 } & & GB10 & 683.3 & 0.46 & 7 \\
\cline { 3 - 6 } & & GB11 & $\sim 720$ & 7.44 & 125 \\
\cline { 3 - 6 } & GB12 & $\sim 720$ & 14.63 & 202 \\
\hline \multirow{2}{*}{ SS-3 } & $800 \mathrm{H}$ & AR2 & \multirow{2}{*}{580} & 1.28 & 23.3 \\
\hline
\end{tabular}

Table 2. Compositions in weight percent (wt\%) of the HFIR samples, with Fe as balance.

\begin{tabular}{|c|c|c|c|c|c|c|c|c|c|c|c|c|c|c|c|}
\hline Alloy & $\mathrm{Cr}$ & $\mathrm{Ni}$ & $\mathrm{Mn}$ & $\mathrm{Si}$ & $\mathrm{Ti}$ & $\mathrm{V}$ & $\mathrm{W}$ & $\mathrm{Mo}$ & $\mathrm{Nb}$ & $\mathrm{Cu}$ & $\mathrm{C}$ & $\mathrm{N}$ & $\mathrm{P}$ & $\mathrm{S}$ & $\mathrm{B}$ \\
\hline G92-2b & 8.9 & 0.1 & 0.47 & 0.14 & & 0.23 & 1.9 & 0.43 & 0.11 & & 0.087 & 0.045 & & & $<$ \\
& & & & & & & & & & & & & & &
\end{tabular}




\subsection{IRRADIATION CONDITIONS}

Some of the irradiation temperatures are reported according to the analyzed results of the accompanied $\mathrm{SiC}$ temperature monitor samples irradiated with the selected samples, while the approximate irradiation temperatures with a " $\sim$ " sign in Table 1 are estimated from extrapolation according to the available SiC temperature monitor results. Figure 1 shows the analyzed temperature from the available SiC temperature monitor samples in the same irradiation campaign as a function of irradiation dose in a logarithmic scale. Each dose has three temperature data points from the SiC samples at the top, middle, and bottom sections of irradiation capsules, which are not differentiated in the plot. The bottom section had relatively stable temperatures, while the top section had relatively large variations with increasing doses. The middle section generally had the highest temperatures, especially at higher doses.

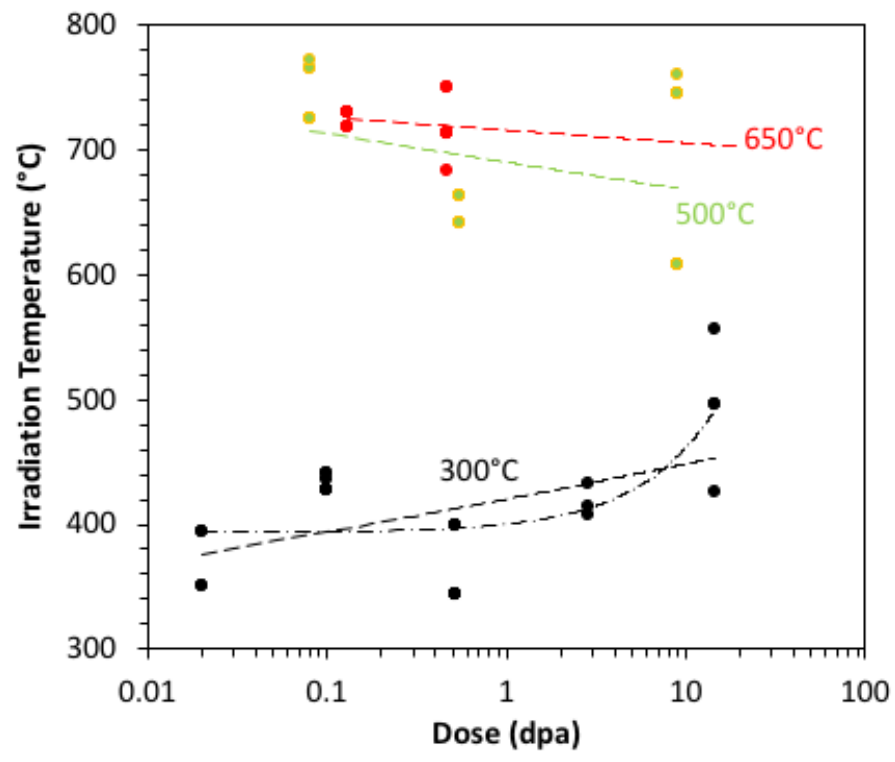

Figure 1. Irradiation temperature as a function of dose of steel samples irradiated with the G92-2b samples.

The dose-dependent irradiation temperature data are roughly fitted with a power function as shown in dashed lines in Figure 1, while the $300^{\circ} \mathrm{C}$ data also exhibited a better fitting by a linear function as shown in a dash-dot line. In general, the planned $300^{\circ} \mathrm{C}$ irradiation turns out to be above $\sim 350^{\circ} \mathrm{C}$ and increasing with higher doses, especially for doses above $3 \mathrm{dpa}$. In contrast, the planned 500 and $650^{\circ} \mathrm{C}$ irradiations had similar irradiation temperatures above $600^{\circ} \mathrm{C}$, tending to slightly decrease with increasing doses. According to Figure 1, it is expected that GB04 at the middle section of the irradiation capsule were irradiated at $\sim 490^{\circ} \mathrm{C}$, while GB11 and GB12 at the middle section of the irradiation capsule was irradiated at $\sim 720^{\circ} \mathrm{C}$. The irradiation temperatures were $\sim 100-200^{\circ} \mathrm{C}$ and $\sim 30-70^{\circ} \mathrm{C}$ higher than the planned 300 and $650^{\circ} \mathrm{C}$. One of the factors causing such large increases from the planned temperatures would be gamma heat generated from tungsten samples that were irradiated with the steel samples in the same capsules. The selected Grade 92 samples irradiated in the Advanced Test Reactor (ATR) of Idaho National laboratory were irradiated at temperatures in the range of $241-431^{\circ} \mathrm{C}$, which will provide lowtemperature properties to have an overall picture about radiation resistance of Grade 92.

The overall irradiation temperatures and doses relevant to this project were reported for different materials including Grade 92, T91, 800H and 800H-TMP [1] [2] [13]. This report includes the result of 
the ORNL samples which were irradiated in HFIR. Figure 2 shows the irradiation temperatures and doses for the ORNL samples. In this report, the irradiation temperatures for G92-2b has two ranges, i.e., higher temperature at $683.3^{\circ} \mathrm{C}-\sim 720^{\circ} \mathrm{C}$ and lower temperature at $400^{\circ} \mathrm{C}-496.7^{\circ} \mathrm{C}$, while both $800 \mathrm{H}$ and 800 TMP are at $580^{\circ} \mathrm{C}$.

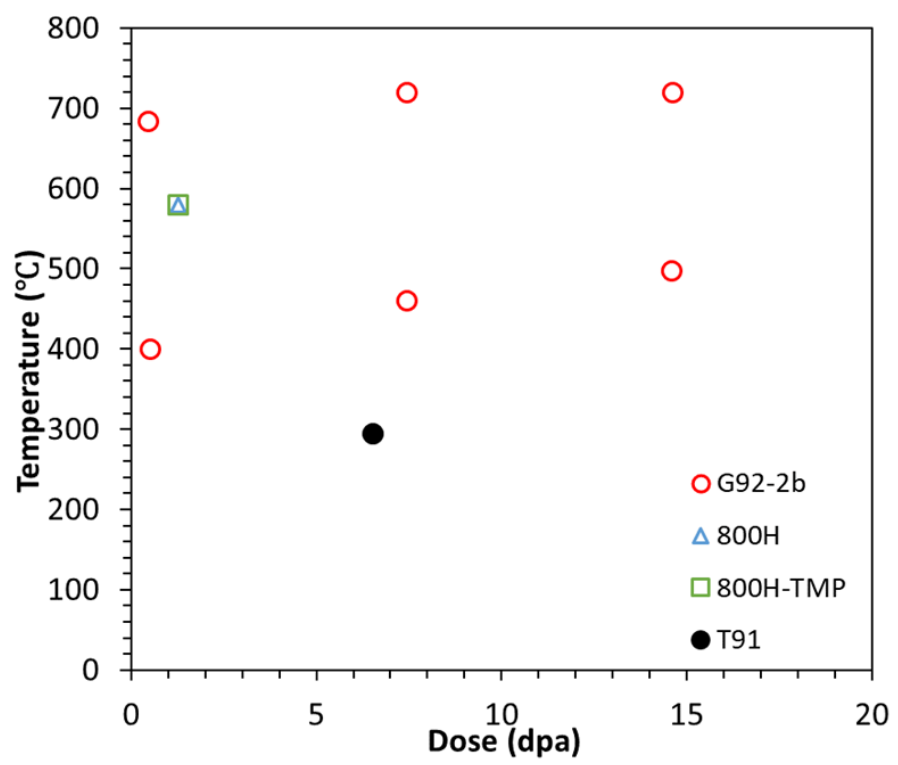

Figure 2. Irradiation temperature and dose conditions of the ORNL samples.

\subsection{SELECTED LANL SAMPLES}

A low-temperature-irradiated T91 sample was selected to be compared with NF616 irradiated at a similar temperature. The T91 sample is designated as TA04, irradiated in ATR at $\sim 295^{\circ} \mathrm{C}$ to $\sim 6.5 \mathrm{dpa}$. The sample condition is listed in Table 3, together with an unirradiated sample TA\#1c. The composition of T91 is listed in Table 4. Both TA04 and TA\#1c samples were tensile tested at room temperature, with the results reported by Maloy et al [14]. The samples received at ORNL were hole-punched from the tab section of the tensile-tested samples.

Table 3. Selected LANL samples.

\begin{tabular}{|c|c|c|c|c|c|c|}
\hline $\begin{array}{c}\text { Specimen } \\
\text { type }\end{array}$ & Alloy & Sample ID & $\begin{array}{c}\text { Temperature } \\
\left({ }^{\circ} \mathrm{C}\right)\end{array}$ & $\begin{array}{c}\text { Dose } \\
(\mathrm{dpa})\end{array}$ & $\begin{array}{c}\text { Irradiation } \\
\text { reactor }\end{array}$ & Comment \\
\hline $\begin{array}{c}\text { Type SS-J2 } \\
\text { tensile }\end{array}$ & \multirow{2}{*}{ T91 } & TA04 & 295 & 6.5 & \multirow{2}{*}{ ATR } & $\begin{array}{c}\text { Tensile-tested at } \\
25^{\circ} \mathrm{C}[14]\end{array}$ \\
\cline { 3 - 5 } & TA\#1c $\mathrm{c}^{\text {a }}$ & & 0 & & \\
\hline
\end{tabular}

${ }^{a}$ Unirradiated control sample of the irradiated T91 (i.e. TA04)

Table 4. Composition in weight percent (wt\%) of the LANL samples, with Fe as balance.

\begin{tabular}{|c|c|c|c|c|c|c|c|c|c|c|c|c|c|c|c|}
\hline Alloy & $\mathrm{Cr}$ & $\mathrm{Ni}$ & $\mathrm{Mn}$ & $\mathrm{Si}$ & $\mathrm{Ti}$ & $\mathrm{Al}$ & $\mathrm{V}$ & $\mathrm{W}$ & $\mathrm{Mo}$ & $\mathrm{Nb}$ & $\mathrm{Cu}$ & $\mathrm{C}$ & $\mathrm{N}$ & $\mathrm{P}$ & $\mathrm{S}$ \\
\hline T91 $^{*}$ & 9.22 & 0.18 & 0.46 & 0.24 & 0.002 & 0.009 & 0.24 & 0.013 & 0.96 & 0.063 & 0.087 & 0.052 & 0.057 & 0.016 & 0.001 \\
\hline
\end{tabular}

${ }^{*}$ Also reported $0.002 \mathrm{O}$ and $0.021 \mathrm{Co}$. The steel was normalized at $1040^{\circ} \mathrm{C}$ for $1 \mathrm{~h}$ with air cooling and tempered at $760^{\circ} \mathrm{C}$ for $1 \mathrm{~h}$ with air cooling [14]. 


\section{HARDNESS TEST RESULTS}

The HFIR-irradiated G92-2b and 800H/800H-TMP, and ATR-irradiated T91 samples were mechanically polished to a mirror finish for Vickers hardness measurements and microstructural characterization. Vickers hardness measurements were conducted at three levels of loads of $0.1,0.5$, and $1 \mathrm{kgf}$ with three measurements per load. Figure 3a shows the average Vickers hardness with standard deviation of the control and irradiated G92-2b and T91. For G92-2b, some hardening was shown in the two samples irradiated at lower temperatures, i.e., $\sim 12 \%$ hardening of GB03 $\left(0.52\right.$ dpa at $\left.400^{\circ} \mathrm{C}\right)$ and $\sim 8 \%$ hardening of GB04 (7.44 dpa at $\sim 490^{\circ} \mathrm{C}$ ). GB05 has a higher dose of 14.66 dpa but shows $\sim 14 \%$ softening due to the longer exposure at irradiation temperature of $496.7^{\circ} \mathrm{C}$. The higher irradiation temperatures $\left(683.3^{\circ} \mathrm{C}\right.$ to $\sim 720^{\circ} \mathrm{C}$ ) resulted in larger softening of $\sim 8 \%, \sim 8 \%$, and $\sim 40 \%$ in GB10, GB11, and GB12, respectively. For T91, the Vickers hardness of irradiated TA04 is shown in Figure 3a. However, the unirradiated T91 sample (TA\#1c) was dislodged from the epoxy during the polishing, leading to the sample being too thin to measure its Vickers hardness. Therefore, the Vickers hardness was not obtained from the sample TA\#1c. From the literature, the Vickers hardness on unirradiated T91 is 210.2 $\pm 4.2 \mathrm{HV}$ [15]. The hardness of the irradiated sample T91 (TA04) is likely increased by $\sim 65 \%$.

The Vickers hardness of AR2 and HG1 and the corresponding references are shown in Figure 3b. Both AR2 and HG1 samples show increased hardness after the irradiation. The difference between AR2 and HG1 after irradiation is not significant, with slightly lower hardness for sample AR2 after irradiation.
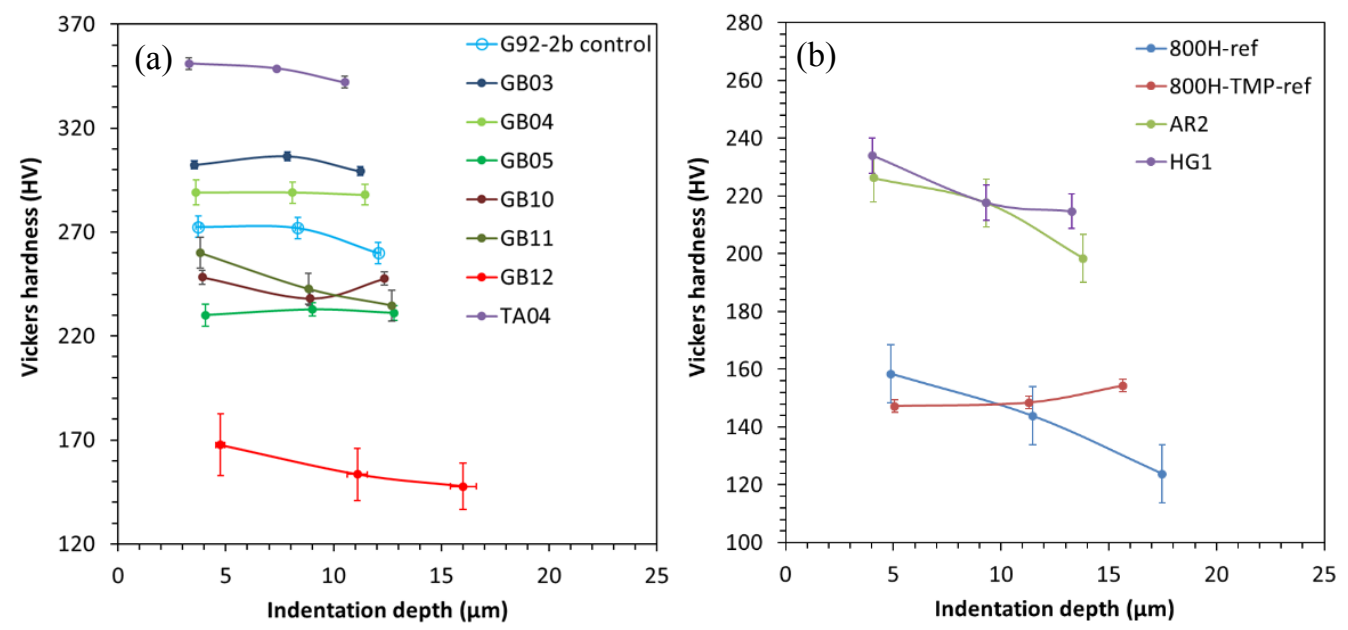

Figure 3. Vickers hardness of (a) G92-2b (GB03-GB12) and T91 (TA04) and (b) 800H (AR2) and 800H-TMP (HG1).

Figure 4 summarizes the dose-dependent hardness at different irradiation temperature of G92-2b. Hardness is dependent on radiation hardening and radiation-enhanced recovery. Sample GB03, GB04, GB05 were irradiated at the lower temperatures range $\left(400^{\circ} \mathrm{C}-496.7^{\circ} \mathrm{C}\right)$ and they have less recovery effect. Thus, these samples show higher hardness than the GB10, GB11, GB12 that were irradiated at $683.3^{\circ} \mathrm{C}-\sim 720^{\circ} \mathrm{C}$. Although GB05 and GB12 have a larger irradiation dose than the other samples, they have lower hardness than other samples in similar irradiation temperatures. This indicates a stronger recovery effect than the radiation hardening effect for these samples. 


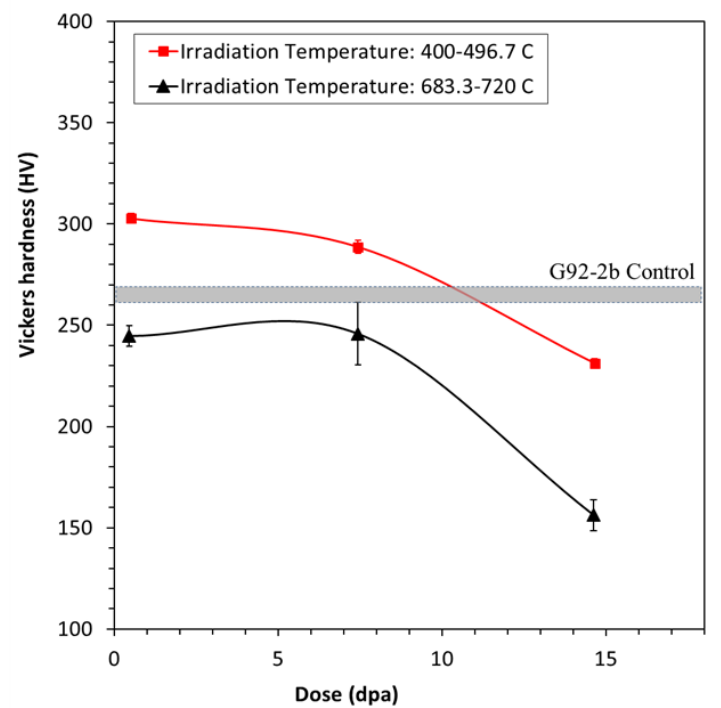

Figure 4. Dose dependence of G92-2b at high and low irradiation temperature. 


\section{MICROSTRUCTURAL CHARACTERIZATION}

Fractography was performed on the fracture surface of the tensile-tested samples using scanning electron microscopy (SEM) and energy dispersive x-ray spectroscopy (EDS) prior to sample polishing. Microstructure of the samples were characterized using electron backscatter diffraction (EBSD) on the polished samples and transmission electron microscopy (TEM) on electron transparent thin lamellae prepared by focused-ion beam (FIB) for lift-outs from the polished samples.

\subsection{FRACTOGRAPHY}

Fractography analysis was conducted on the tensile-tested samples of G92-2b and $800 \mathrm{H}$ and $800 \mathrm{H}-\mathrm{TMP}$ but not on the disc samples of T91 because of the lack of tensile-tested samples.

\subsubsection{Grade 92 - Heat G92-2b}

Figure 5 shows the fractography of the tensile-tested G92-2b samples, including GB03, GB10, GB11. The tensile tests were conducted at room temperature. GB03 (0.52 dpa) and GB10 (0.46 dpa) that have a similar low dose showed more evident necking than the higher dose sample GB11 (7.44 dpa). GB11 shows large dimple size, on the order of a few micrometers. Nb-containing particles were observed inside some of the dimples, and these particles have a size of a few hundred nanometers. Clustering of $\mathrm{Nb}$ containing particles is present inside dimples in GB11, as arrow-pointed in the inset of Figure $5 \mathrm{f}$.

Compared with the fractography of samples GB04, GB05, and GB12 that was reported previously [1] [2], GB03, GB04, and GB05 irradiated at $400^{\circ} \mathrm{C}-496.7^{\circ} \mathrm{C}$ showed evident necking at different doses, while GB10, GB11, and GB12 irradiated at $683.3-720^{\circ} \mathrm{C}$ showed dose-dependent necking. GB10 (0.46 dpa) showed evident necking, while higher dose samples, especially GB12 (14.66 dpa), did not show significant necking [1] [2]. The fractography result is in agreement with the tensile test results [1] [2], with the ductility of G92-2b maintained up to $14.66 \mathrm{dpa}$ at the lower irradiation temperatures of $400^{\circ} \mathrm{C}$ $496.7^{\circ} \mathrm{C}$, while some loss of ductility (smaller necking and smaller elongation) for higher doses at irradiation temperatures of $683.3^{\circ} \mathrm{C}-720^{\circ} \mathrm{C}$.
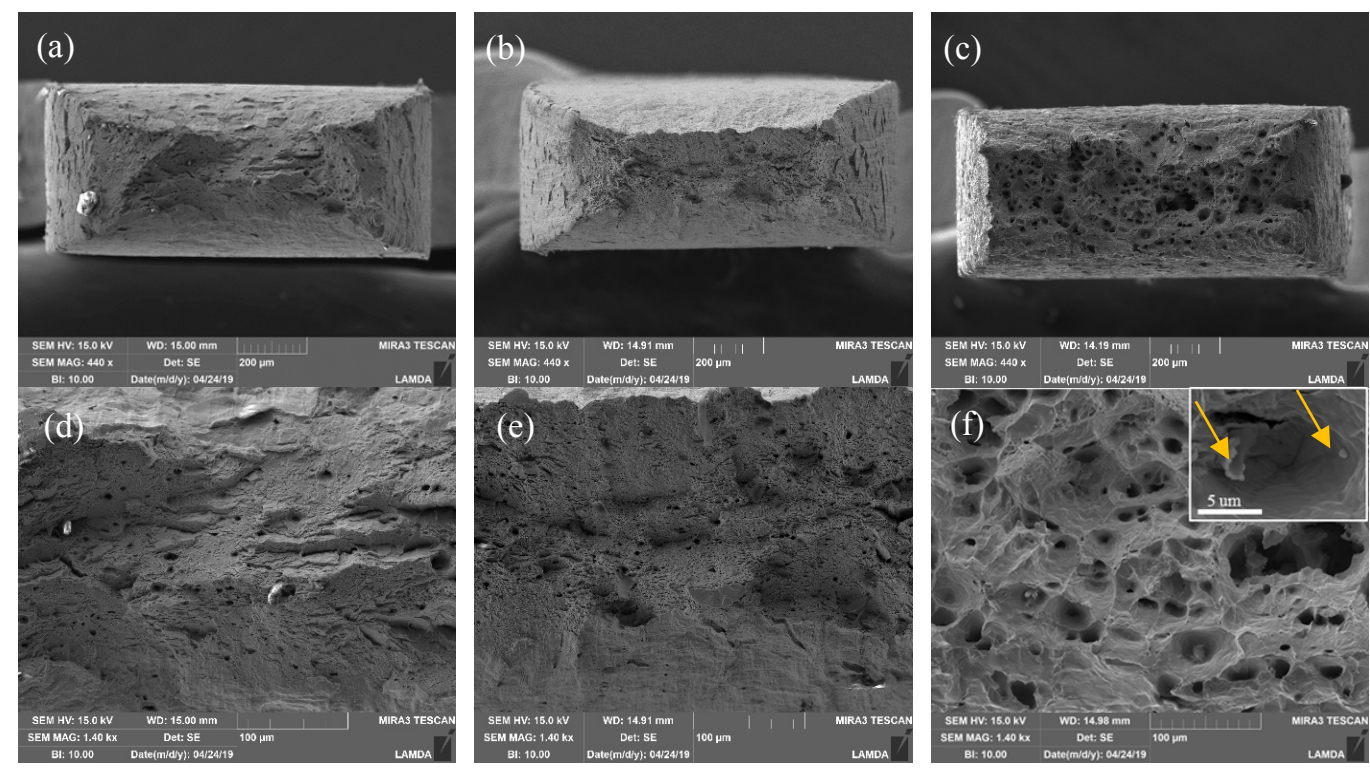

Figure 5. Fractography of the tensile tested (a, d) GB03, (b, e) GB10, (c, f) GB11 samples. 


\subsection{2 $\quad 800 \mathrm{H} / 800 \mathrm{H}-\mathrm{TMP}$}

Figure 6 shows the fractography of the tensile-tested AR2 and HG1. Both samples showed intergranular cracking, with negligible necking. Large grains were observed on both AR2 and HG1, with twin boundaries often seen in the HG1 sample, as shown in Figure 6e. This is in an agreement with the thermomechanical processing effect on $800 \mathrm{H}-\mathrm{TMP}$ that has more twinning in the pre-irradiated state. Large TiC particles were observed in a few micrometers at the fracture surface of both samples. $\mathrm{M}_{23} \mathrm{C}_{6}$ precipitates were occasionally shown inside the large TiC precipitates, as shown in Figure 6c.
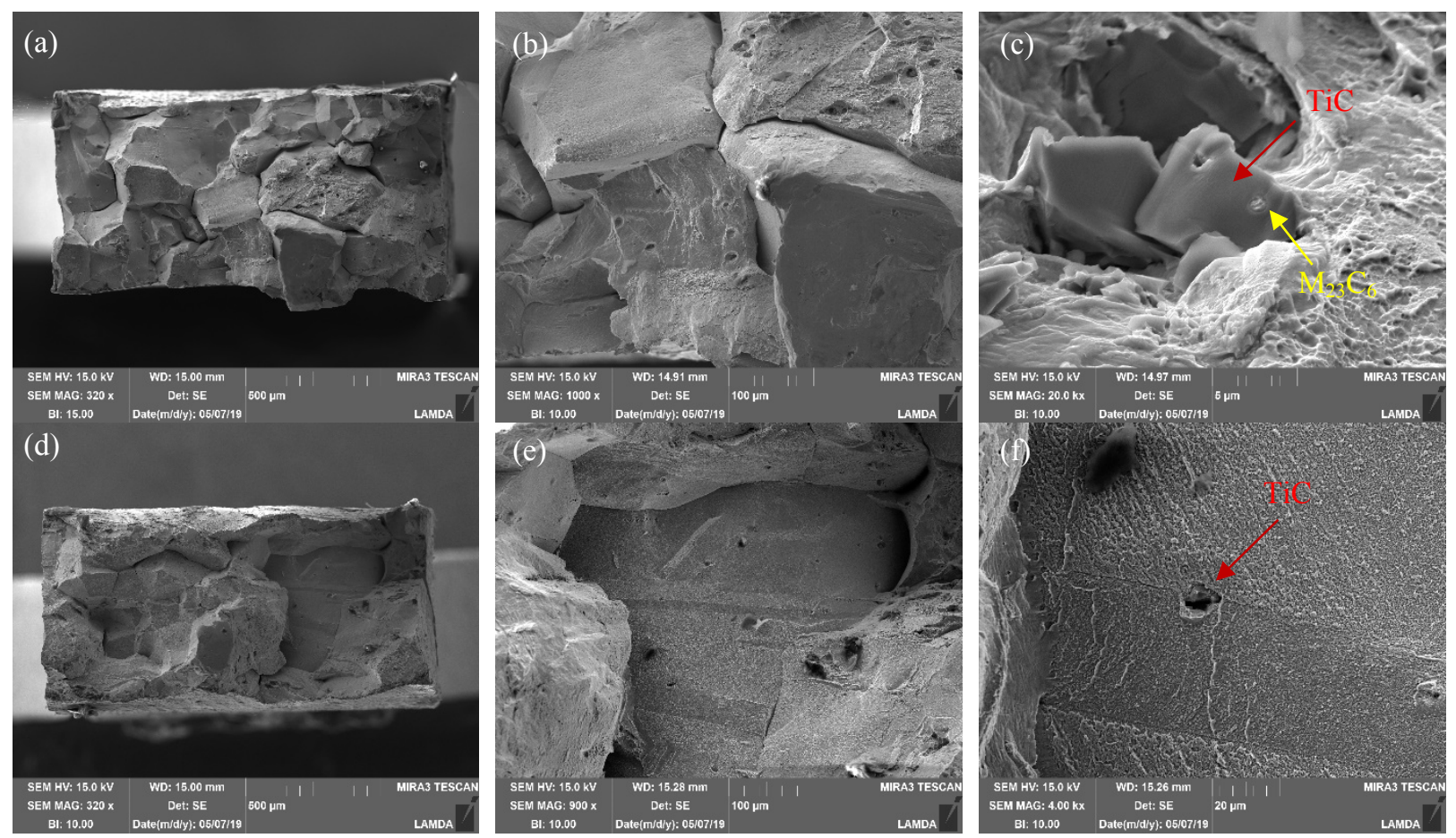

Figure 6. Fractography of the tensile tested (a, b, c) AR2 and (d, e, f) HG1 samples.

\subsection{EBSD RESULTS}

\subsubsection{Grade 92 - unirradiated G92-2b and GB12 (14.63 dpa at $\left.\sim 720^{\circ} \mathrm{C}\right)$}

EBSD was performed on the archived unirradiated G92-2b and the irradiated GB12. Figure 7 shows the EBSD results in inverse pole figure of the two samples at two levels of magnification. The unirradiated G92-2b showed typical martensitic morphology, as shown in Figure 7a and Figure 7b. In contrast, GB12 lose the fine lath martensitic structure after irradiation at $\sim 720^{\circ} \mathrm{C}$, which showed coarse approximately equiaxed grain morphology, as shown in Figure 7c. The high magnification image of GB12 in Figure 7d shows that the larger grain is generally consisted of small domains with low angle boundaries. 


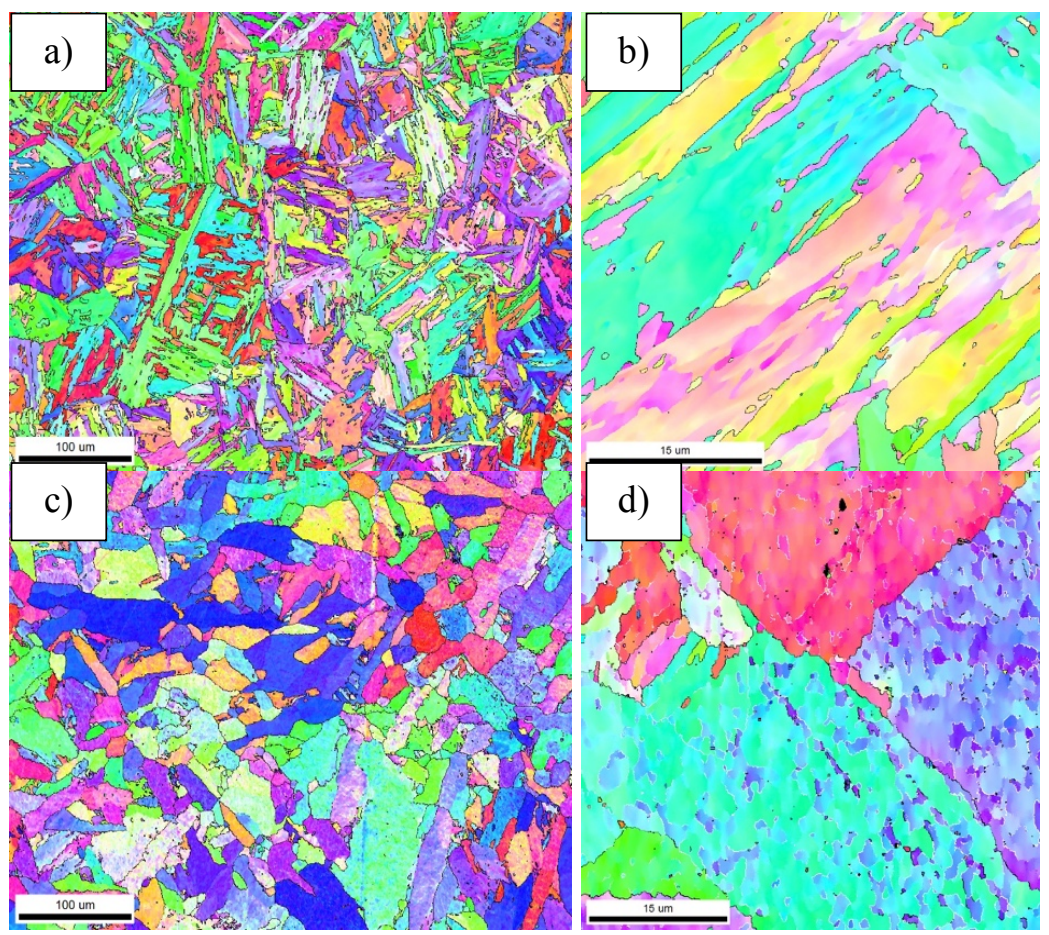

Figure 7. EBSD results of (a, b) archived unirradiated G92-2b and (c, d) GB12.

\subsection{TEM RESULTS}

\subsubsection{Grade 92 - unirradiated G92-2b}

Figure 8 shows the microstructure of the unirradiated G92-2b, illustrating a lath structure with width ranging from $100 \mathrm{~nm}$ to $400 \mathrm{~nm}$. Precipitates $\mathrm{M}_{23} \mathrm{C}_{6}(\mathrm{M}=\mathrm{Cr}$ primarily) mainly decorated the boundaries, as shown in Figure 8a. The size of $\mathrm{M}_{23} \mathrm{C}_{6}$ precipitates was estimated using $\sqrt{L W}$, where $L$ and $W$ are the length and the width of $\mathrm{M}_{23} \mathrm{C}_{6}$ precipitates. The average size of $\mathrm{M}_{23} \mathrm{C}_{6}$ precipitates was $69 \pm 25 \mathrm{~nm}$. Figure $8 \mathrm{~b}$ shows $\mathrm{V}$-rich MX phase platelet precipitates in the matrix. The image was taken under the twobeam condition of $\mathrm{g}_{200}$ near [001] zone. In addition, $\mathrm{Nb}(\mathrm{C}, \mathrm{N})$ precipitates are present inside grains, as pointed in Figure $8 \mathrm{c}$. The $\mathrm{Nb}(\mathrm{C}, \mathrm{N})$ precipitates have a spherical morphology with a size of about $25 \mathrm{~nm}$. Figure $8 d$ shows the image of dislocation lines under the [001] zone axis. An average density of $\sim 4 \times 10^{14}$ $\mathrm{m}^{-2}$ for the dislocation lines was estimated from multiple images.
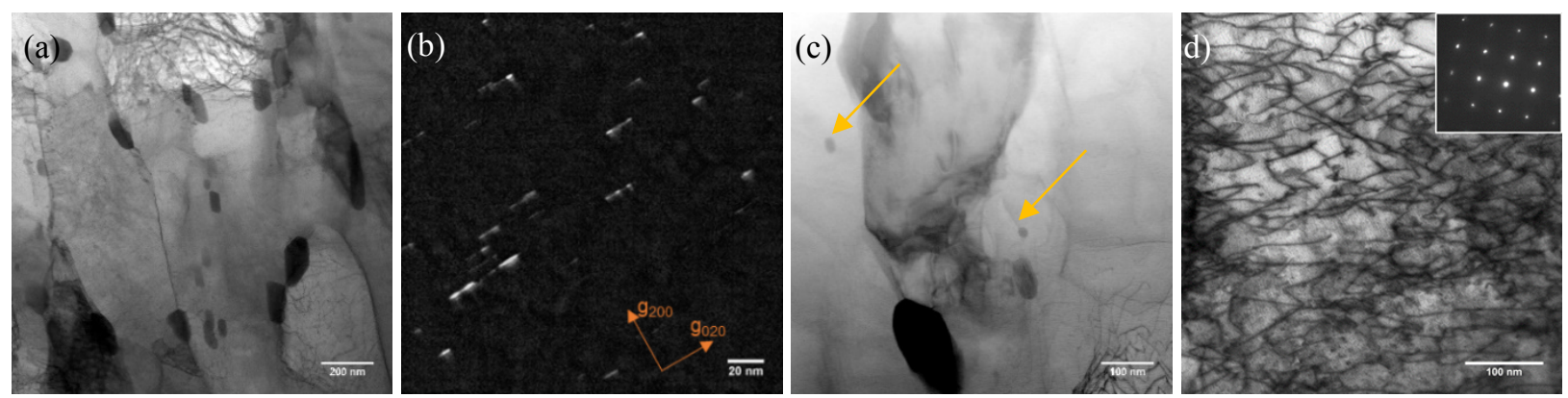

Figure 8. STEM bright field images (a, c, d) and TEM dark field image (b) of the unirradiated G92-2b showing a) $\mathrm{M}_{23} \mathrm{C}_{6}$ precipitates, b) MX precipitates, c) NbN precipitates, and d) dislocations. 


\subsubsection{Grade $92-$ GB03 $\left(0.52 \mathrm{dpa}, 400^{\circ} \mathrm{C}\right)$}

Microstructure was characterized on the tensile-tested irradiated G92-2b at different doses. Figure 9 shows the microstructure of GB03 at the tab section, where it is assumed to be stress free because of the shoulder load during tensile testing. Lath structure seems coarser, with some grains having the width of over $1 \mu \mathrm{m}$ as shown in Figure 9a. Further verification will be pursued. $\mathrm{M}_{23} \mathrm{C}_{6}$ precipitates decorated boundaries, which have an elongated shape along boundaries as shown in Figure $9 \mathrm{~b}$. Spherical $\mathrm{Nb}(\mathrm{C}, \mathrm{N})$ precipitates are distributed within grains, which have sizes from $20 \mathrm{~nm}$ to $30 \mathrm{~nm}$. Figure 9c shows a $\mathrm{Nb}(\mathrm{C}, \mathrm{N})$ precipitate having a core-shell structure. The fast Fourier transform (FFT) of the core indicates the [011] zone of $\mathrm{Nb}(\mathrm{C}, \mathrm{N})$ precipitate in the inset of Figure 9c. The lattice parameter of $\mathrm{Nb}(\mathrm{C}, \mathrm{N})$ precipitate was measured to be $4.457 \pm 0.086 \AA$. A cluster of precipitates at a grain boundary was also observed, as shown in Figure 9d, which include $\mathrm{M}_{23} \mathrm{C}_{6}$ precipitates (pointed by the black arrows), a spherical $\mathrm{Nb}$-rich precipitate (pointed by the orange arrow), and a $\mathrm{V}$-rich precipitate (pointed by the red arrow). Figure 9e shows the dark field image of MX platelet precipitates, similar to the MX in the unirradiated sample in Figure $8 \mathrm{~b}$. The dark field image was taken under the two-beam condition of $\mathrm{g}_{200}$ near [011] zone. Figure 9f shows the dislocation lines, taken under the [001] zone.
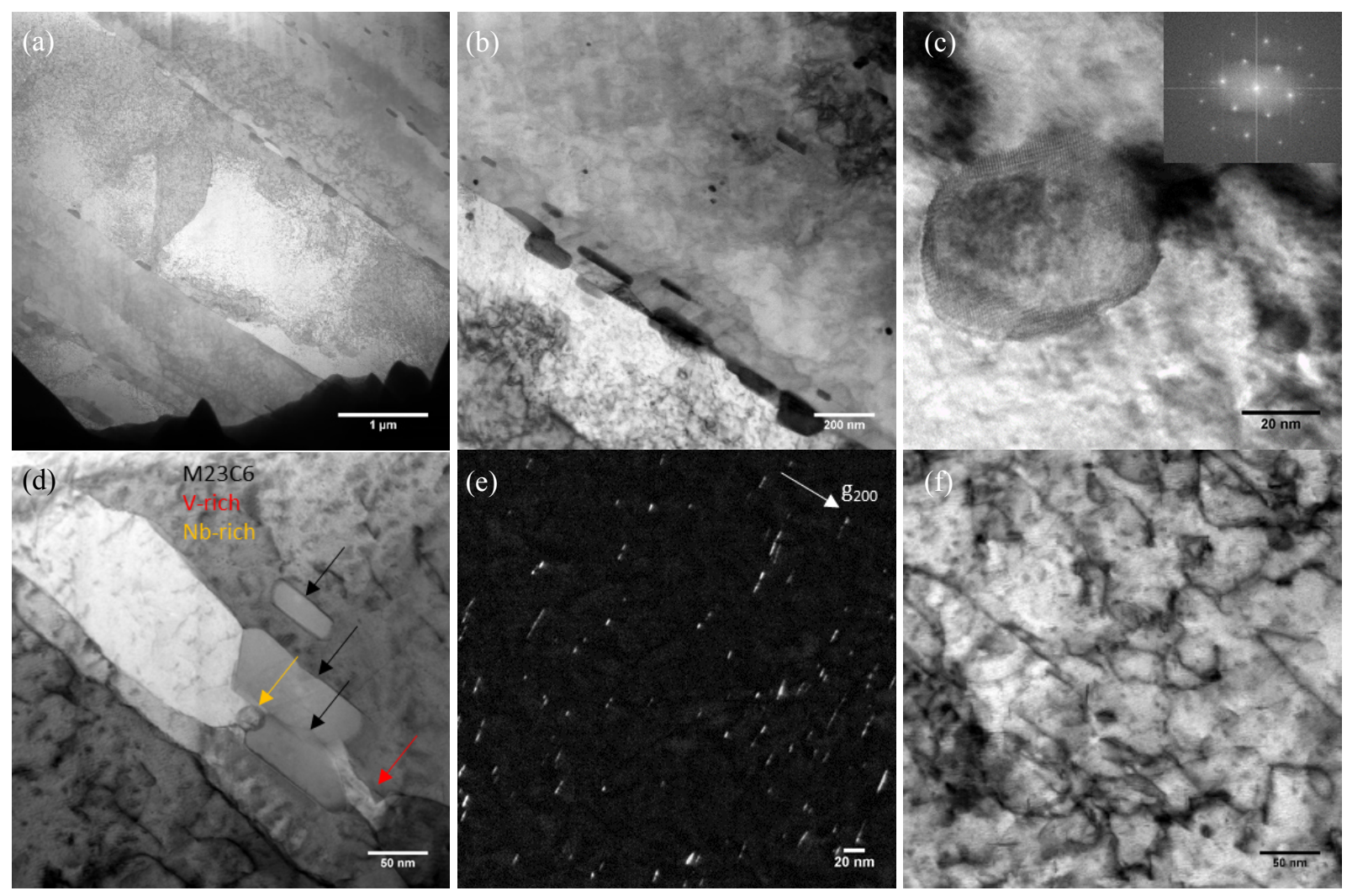

Figure 9. STEM (a, b, c, d, f) bright field images, and (e) TEM dark field image of GB03 at the tab section.

The microstructure of the gauge section of GB03 is shown in Figure 10. Figure 10a shows the $\mathrm{M}_{23} \mathrm{C}_{6}$ precipitates at grain boundaries, as pointed by the blue arrows. Cavities are present and accumulated at the phase boundaries, as pointed by the white arrows in Figure 10a. Figure 10b shows a twinning domain in the center of the image, which has a width of $140 \mathrm{~nm}$. The diffraction patern of the twin is shown in Figure 10c, taken under the [011] zone axis. Multiple precipitates decorated the boundaries beside the twin, including $\mathrm{M}_{23} \mathrm{C}_{6}$ precipitates (pointed by the blue arrows), spherical Nb-rich precipitate (pointed by the orange arrow), and V-rich precipitates (pointed by the yellow arrow). The V-rich precipitate was identified by EDS as it does not have strong contrast under STEM. 

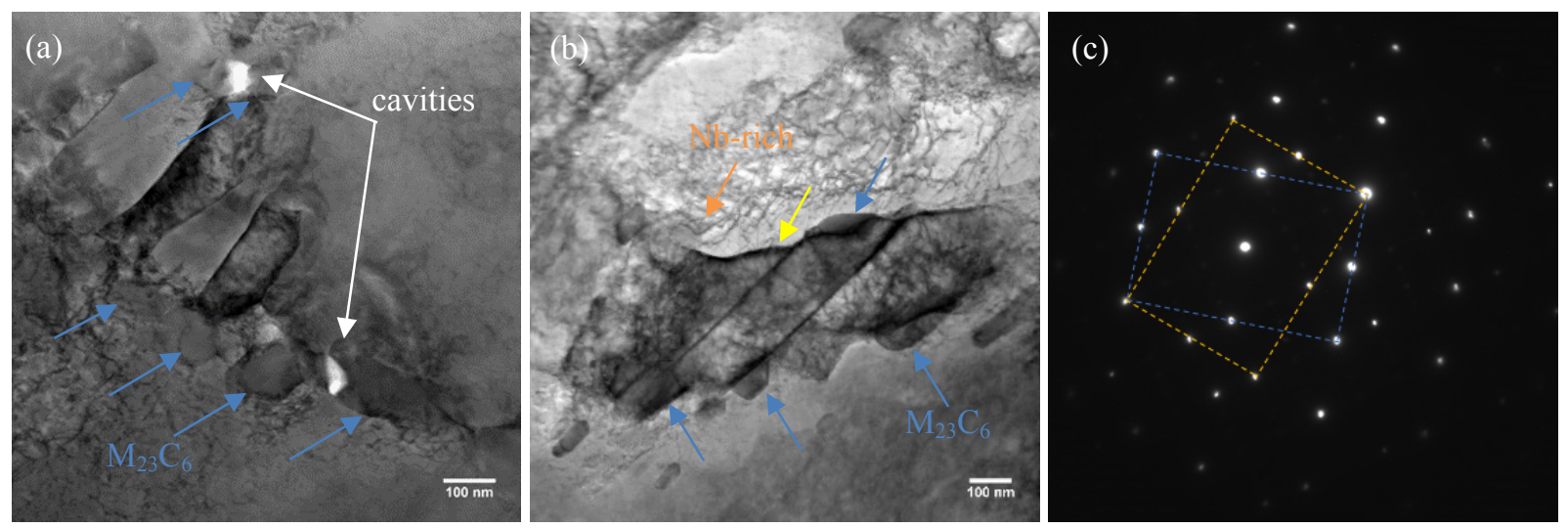

Figure 10. STEM (a, b) bright field images and (c) the diffraction patterns of the twin in (b) of GB03 at the gauge section.

\subsubsection{Grade $92-$ GB10 $\left(0.46\right.$ dpa, $\left.683.3^{\circ} \mathrm{C}\right)$}

Figure 11 shows the microstructure of the tab section of GB10. Lath structure grew under the elevated irradiation temperature at $683^{\circ} \mathrm{C}$, as shown in Figure 11a, with some laths having a width of $\sim 1 \mu \mathrm{m}$. Figure $11 \mathrm{~b}$ shows the dislocation lines taken under the [111] zone, and the dislocation density is $\sim 1.2 \mathrm{x}$ $10^{14} \mathrm{~m}^{-2}$. The reduction of dislocation density is attributed to the annealing effect at $683^{\circ} \mathrm{C} . \mathrm{M}_{23} \mathrm{C}_{6}$ precipitates mainly docorated boundaries, as shown in Figure $11 \mathrm{c}$. Some $\mathrm{M}_{23} \mathrm{C}_{6}$ precipitates grows into spherical shape at the triple-junction of boundaries, as shown in the Figure 11d. A Laves phase precipitate was also observed, as pointed in Figure 11e. The Laves phase precipitate shows a highly faulted structure adjacent to a $\mathrm{M}_{23} \mathrm{C}_{6}$ precipitate at the boundary. Some V-rich precipitates are accumulated at boundaries, which have sizes of $20-30 \mathrm{~nm}$ and are pointed by the orange arrows in Figure $11 \mathrm{f}$. These precipitates are accumulated at the boundaries of small grains, indicating the pinning effect of $\mathrm{V}$-rich precipiates to grain growth. 

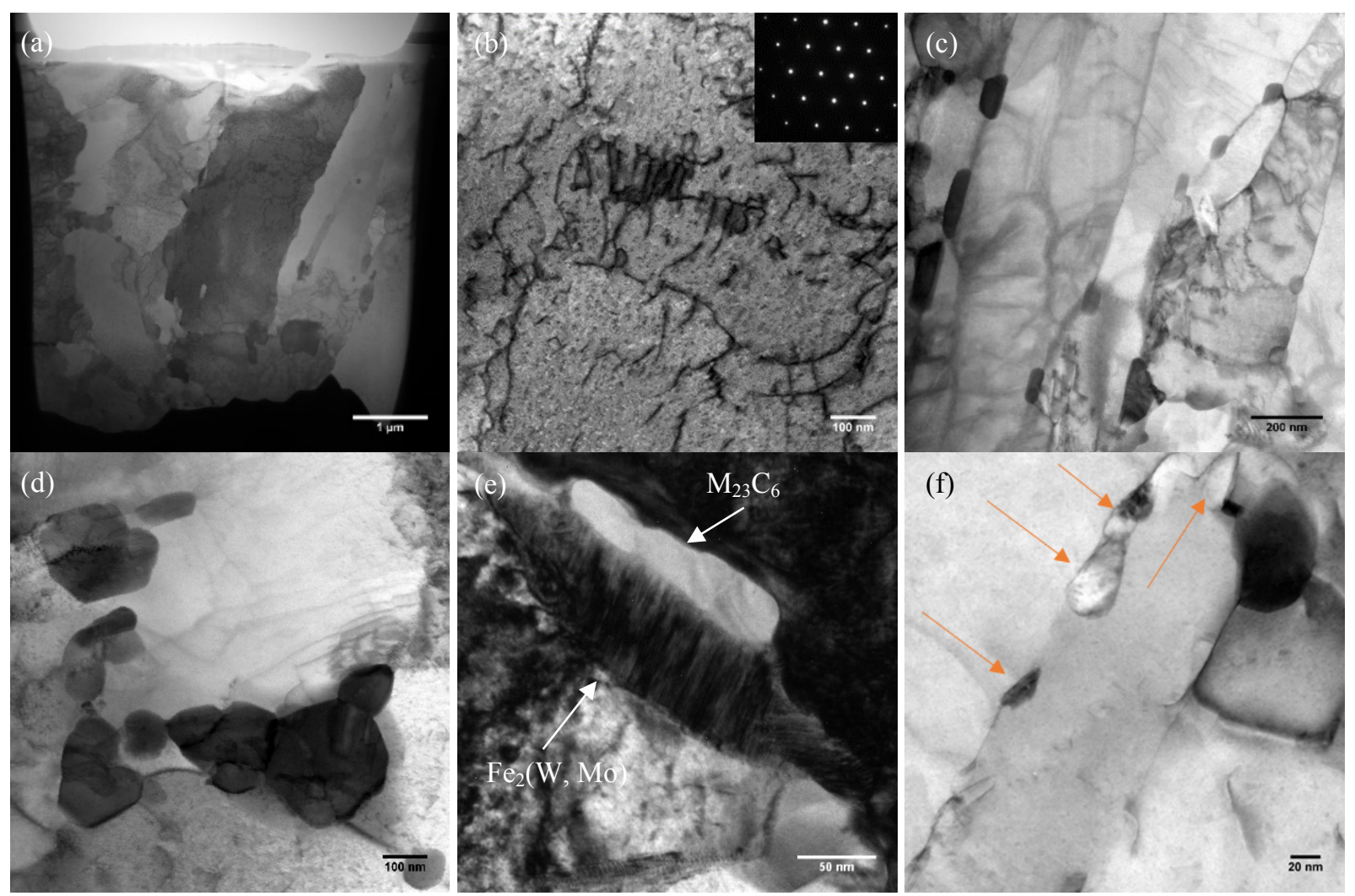

Figure 11. STEM bright field images (a, b, c, d, f) and TEM bright field image (e) of GB10 at the tab section, showing (a) overview, (b) dislocation, (c, d) $M_{23} C_{6}$ precipitates, (e) Laves Phase precipitate, and (f) V-rich precipitates pointed by the orange arrows.

Figure 12 shows the microstructure of the gauge section of GB10, with Figure 12a illustrating the lath structure. Some precipitates were observed at boundaries. Figure $12 \mathrm{~b}$ shows a cluster of precipitates at a boundary, which include $\mathrm{NbN}, \mathrm{M}_{23} \mathrm{C}_{6}$, and $\mathrm{MnS}$ precipitates. $\mathrm{NbN}$ precipitates have a spherical shape with the diameter of $180 \mathrm{~nm}$. The FFT of the $\mathrm{NbN}$ precipitate is shown in Figure 12c, which shows an orientation relationship with the matrix of $[011]_{\mathrm{NbN}} / /[111]_{\text {matrix }}$. The lattice parameter of the $\mathrm{NbN}$ precipitate was determined to be $4.2571 \pm 0.0857$ Angstrom from the FFT. The MnS precipitate with an oval shape is adjacent to the $\mathrm{NbN}$ particle with a size of $75 \mathrm{~nm}$. Two $\mathrm{M}_{23} \mathrm{C}_{6}$ precipitates were identified, with one of them being amorphous as shown in Figure 12d. Crystalline $\mathrm{M}_{23} \mathrm{C}_{6}$ precipitates were also observed, with one of the examples shown in Figure 12e. The diffraction pattern under [112] zone of $\mathrm{M}_{23} \mathrm{C}_{6}$ precipitate is shown as an inset of Figure 12e. The $\mathrm{M}_{23} \mathrm{C}_{6}$ precipitate has an orientation relationship with the matrix of $\{111\}_{\mathrm{M} 23 \mathrm{C} 6} / /\{110\}_{\text {Matrix }}$. Dislocation lines are evident from the STEM bright field image as shown in Figure 12f, taken under the [001] zone. The density of dislocation lines is $2.5 \mathrm{x}^{10^{14} \mathrm{~m}^{-}}$ ${ }^{2}$, higher than the tab section of the sample GB10. 

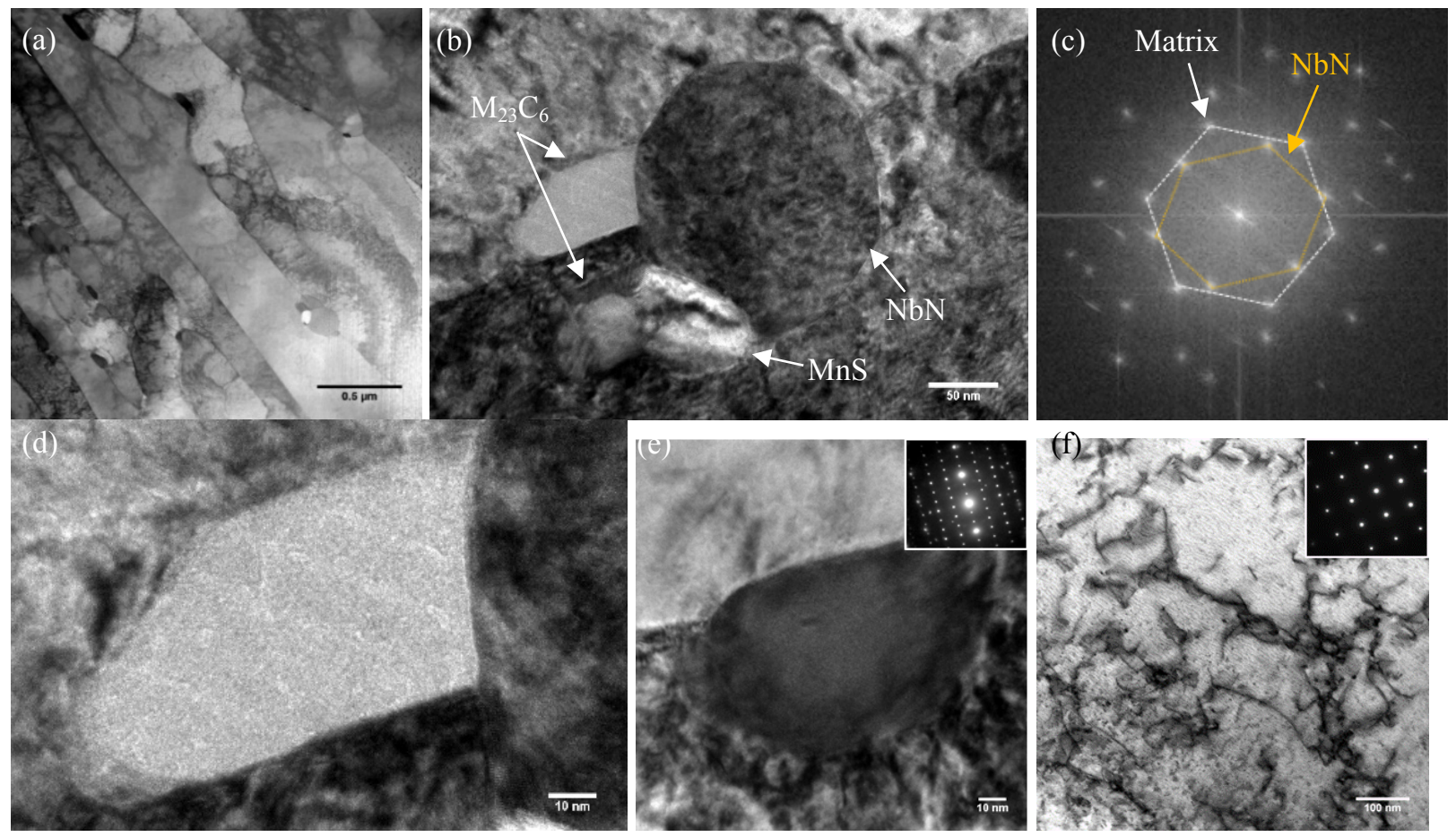

Figure 12. STEM (a, f) bright field images and (b, d, e) TEM bright field images and (e) the FFT of the NbN precipitate of GB10 at the gauge section.

\subsubsection{Grade $92-$ GB11 (7.44dpa, $\left.\sim 720^{\circ} \mathrm{C}\right)$}

GB11 was irradiated at $\sim 720^{\circ} \mathrm{C}$ to $7.44 \mathrm{dpa}$, and this corresponds to the irradiation time of 126 days. Equiaxed grain structure is pronounced in the tab section of sample GB11, as shown in the Figure 13a. A few dislocation walls are evident in the top left grain of Figure 13a, which might be the pre-existing packet and block boundaries. Figure $13 \mathrm{~b}$ shows the dislocation lines under the [001] zone. Voids were observed near dislocation networks, as shown in Figure 13c. Nb shells are observed around voids, as shown in the Nb-maps in Figure 13d.
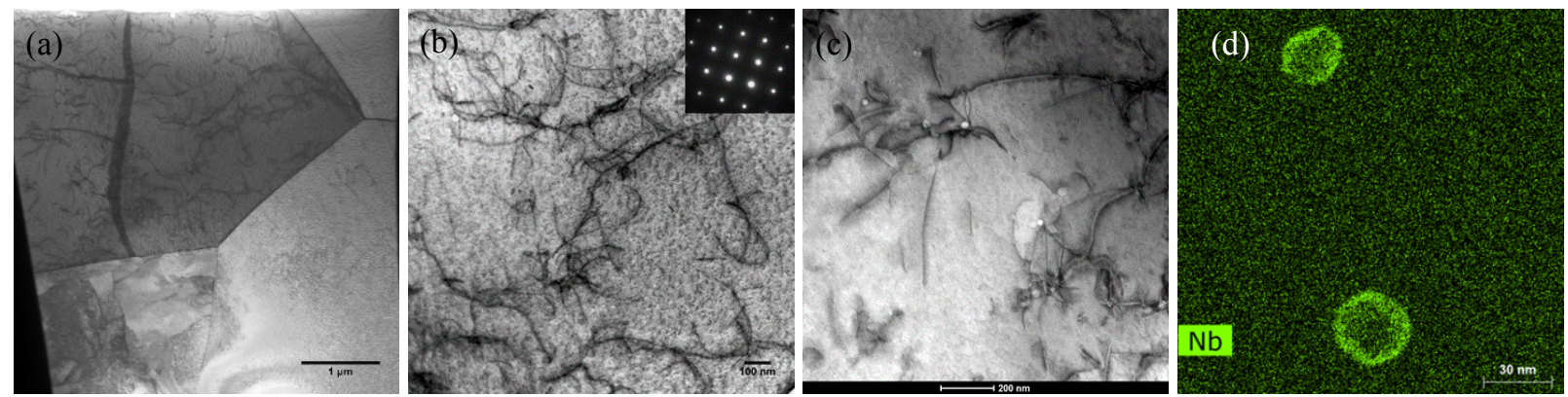

Figure 13. STEM (a, b, c) bright field images, and (d) Nb maps near voids of GB11 at the tab section.

Figure 14 shows the microstructure of GB11 at the gauge section. The TEM foil was lifted out near the fracture site of the tensile specimen, where it had high stress from the tensile test. Dislocation-compiled cells are evident in Figure 14a, with the cell size of hundreds of nanometers. Some dark features accumulated at boundaries, as show in Figure 14b. The dark features are shown in the higher 
magnification image in Figure 14c, which have the same chemical composition as the matrix, and they also have the body-centered cubic structure.
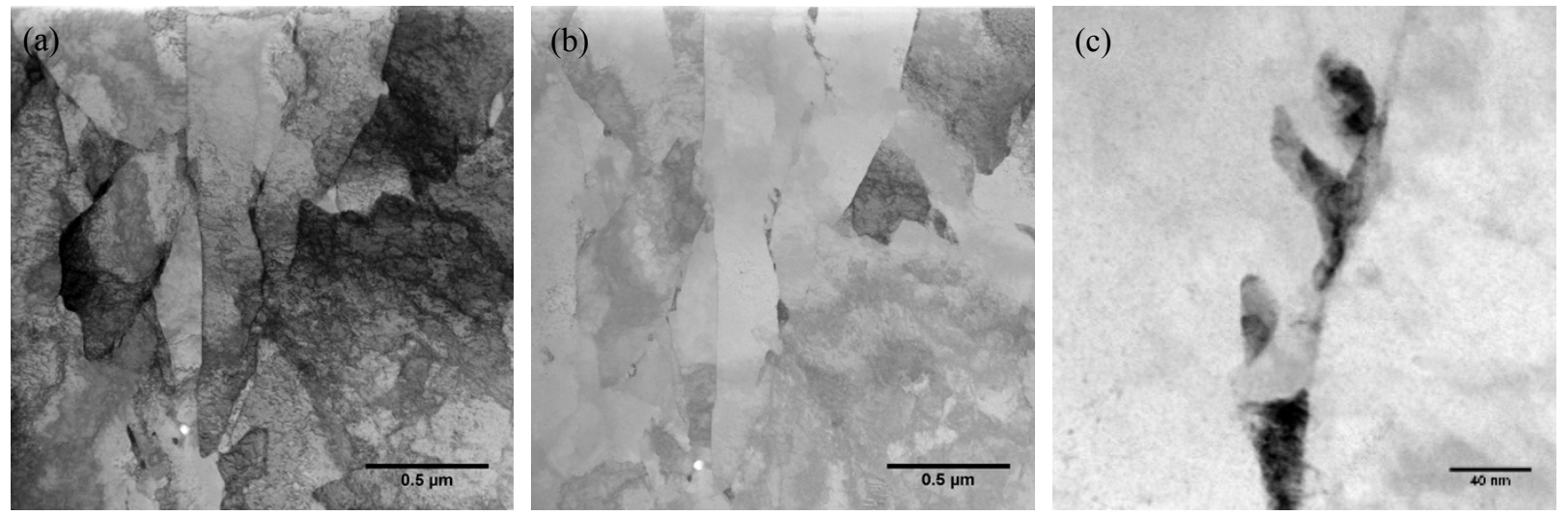

Figure 14. STEM bright field image GB11 at the gauge section.

\subsection{5 $\quad 800 \mathrm{H}-\mathrm{AR2}\left(1.28 \mathrm{dpa}, 580^{\circ} \mathrm{C}\right)$}

Figure 15 shows the microstructure of irradiated $800 \mathrm{H}$ at the tab section. Large $\mathrm{M}_{23} \mathrm{C}_{6}$ precipitates are accumulated at a grain boundary, and they have sizes of $\sim 110 \mathrm{~nm}$, as shown in the Figure $15 \mathrm{a} . \mathrm{M}_{23} \mathrm{C}_{6}$ precipitates are also present inside grains, and they have facet shapes, as shown in the Figure 15b. The diffraction pattern of the $\mathrm{M}_{23} \mathrm{C}_{6}$ precipitates with the matrix is shown in Figure 15c, indicating the cubeon-cube orientation relationship of $\mathrm{M}_{23} \mathrm{C}_{6}$ precipitates with the matrix. Figure $15 \mathrm{~d}$ shows the diffraction pattern of the two-beam condition $\mathrm{g}_{022}$ near [011] zone. Diffraction intensities from $\mathrm{M}_{23} \mathrm{C}_{6}$ and $\gamma^{\prime}$ are observed, which are labeled with orange arrows and a white arrow respectively. This indicates the presence of $\gamma^{\prime}$ precipitates in AR2.
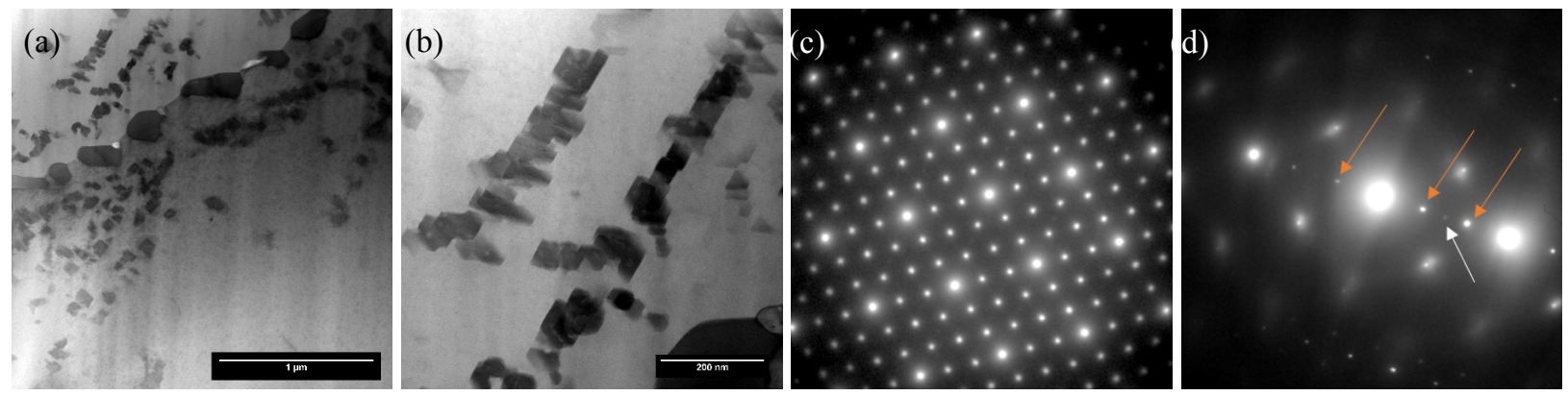

Figure 15. STEM $(a, b)$ bright field images and $(c, d)$ diffraction patterns at the tab section.

The microstructure of the gauge section of sample AR2 is shown in Figure 16. $\mathrm{M}_{23} \mathrm{C}_{6}$ precipitates accumulates at a grain boundary as shown in Figure 16a. Dense dislocation network are evident and shown in Figure 16b. Dislocation loops are also present, as shown in Figure 16c. The image was taken by the rel-rod method using the two-beam condition $\mathrm{g}_{311}$ near [011] zone, as the diffraction pattern shown on the subset in Figure 16c. 

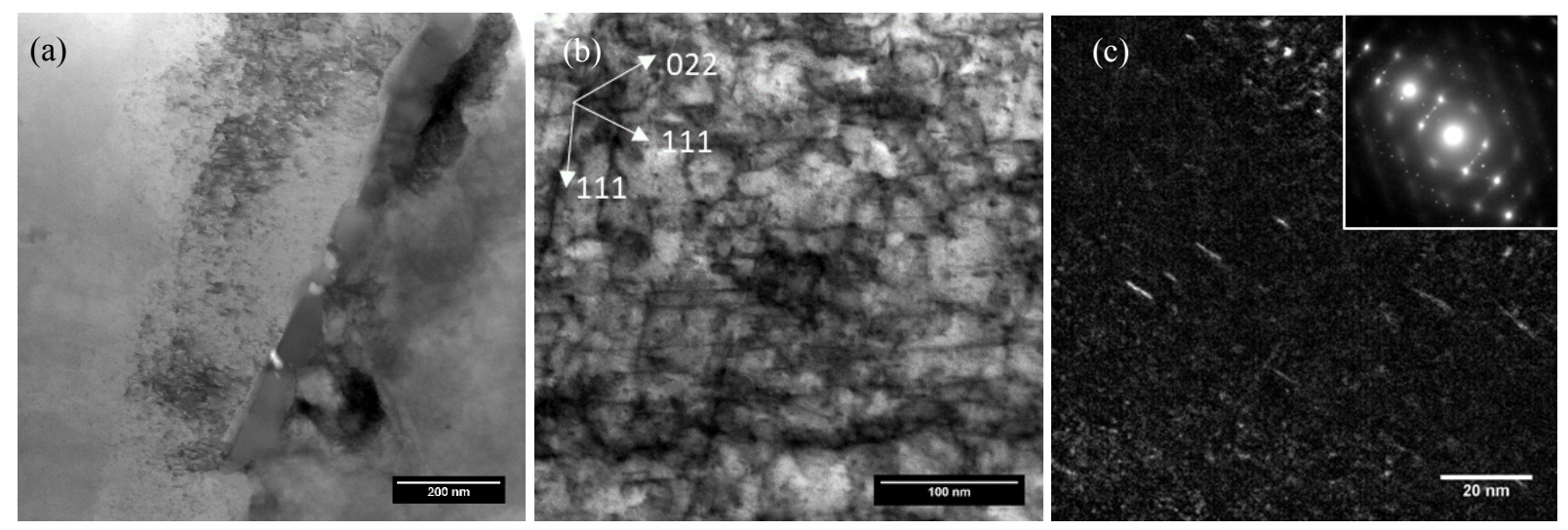

Figure 16. STEM (a,b) bright field images and (c) dark field image on the dislocation loops.

\subsubsection{H-TMP - HG1 (1.28dpa, $\left.580^{\circ} \mathrm{C}\right)$}

Figure 17 shows the microstructure of irradiated $800 \mathrm{H}-\mathrm{TMP}$ at the tab section. Large precipitates are accumulated at grain boundaries, as shown in Figure 17a. Dark precipitates are $\mathrm{M}_{23} \mathrm{C}_{6}$ (pointed by the orange arrows) that has a size of a few hundred nanometers, and some bright TiC precipitates (pointed by the yellow arrows) are embeded inside the $\mathrm{M}_{23} \mathrm{C}_{6}$ precipitates. Within the grain, there are some smaller $\mathrm{M}_{23} \mathrm{C}_{6}$ precipitates that have a facet shape with the size of about $100 \mathrm{~nm}$ as shown in Figure $17 \mathrm{~b}$. This indicates that the $\mathrm{M}_{23} \mathrm{C}_{6}$ has prefered orientation relationship with the matrix. Figure $17 \mathrm{c}$ shows the HRTEM on the interface of the $\mathrm{M}_{23} \mathrm{C}_{6}$ precipitate and the matrix. The FFT shown in the inset shows that the precipitate has the cube-on-cube orientation relationship with the matrix. A nano-scale TiC precipitate exists inside the $\mathrm{M}_{23} \mathrm{C}_{6}$ precipitate, which also has the cube-on-cube orientaion relationship with the $\mathrm{M}_{23} \mathrm{C}_{6}$ precipitate, as indicated by the FFT of the precipitate shown in the inset of Figure $17 \mathrm{~d}$. Figure $17 \mathrm{e}$ shows the dark field image showing the $\gamma^{\prime}$ precipitates distribution. The image was taken under a twobeam condition $\mathrm{g}_{022}$ near the [011] zone, and the diffraction pattern is inset in Figure 17e, where diffraction spots of $\mathrm{M}_{23} \mathrm{C}_{6}$ and $\gamma^{\prime}$ precipitates are labeled with orange and white arrows. Figure $13 \mathrm{f}$ shows the dark field image of dislocation loops, which was taken under a two-beam condition $\mathrm{g}_{311}$ near the [011] zone, and the diffraction pattern is shown in the inset of Figure 13f. 

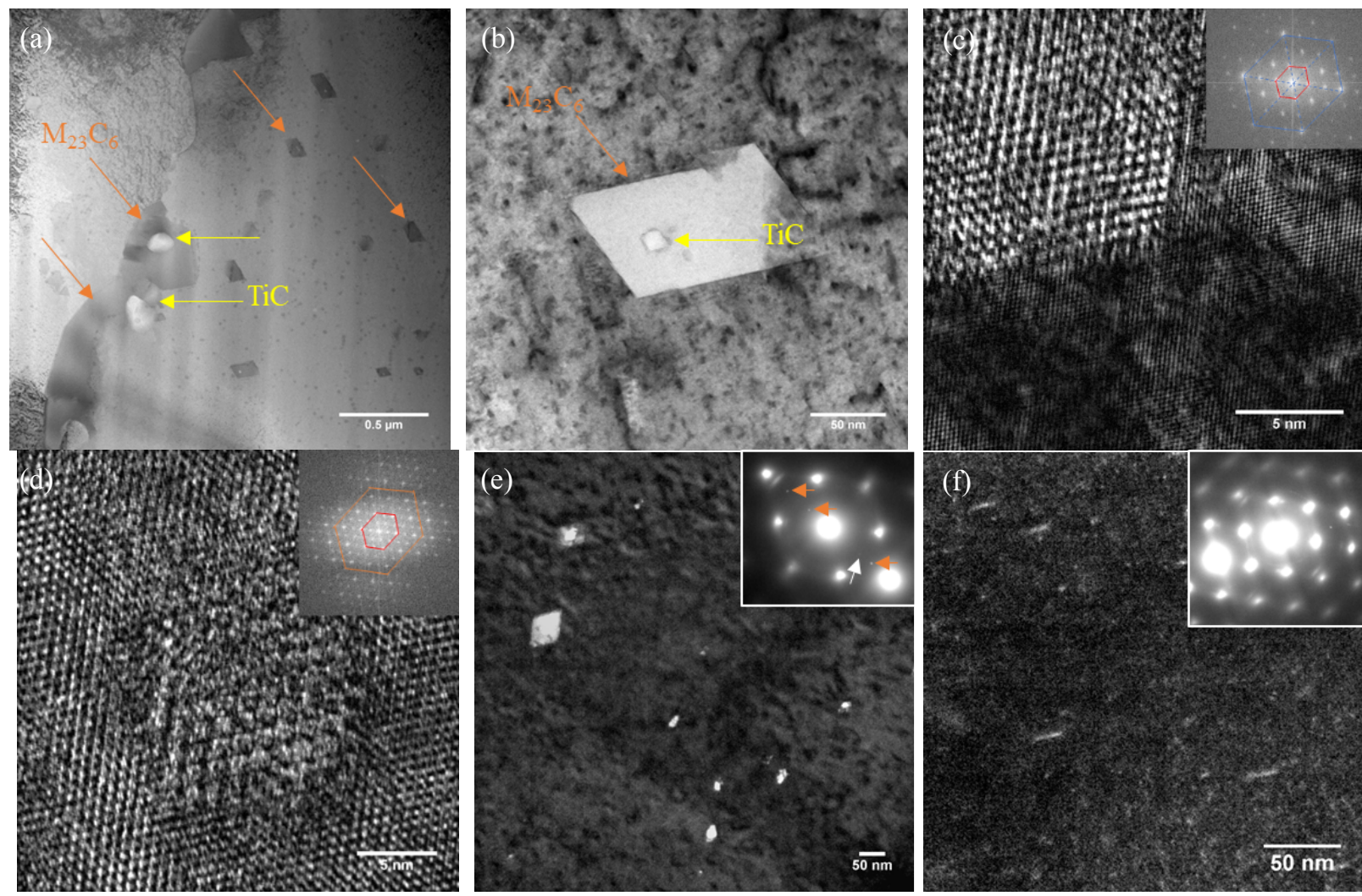

Figure 17. STEM (a, b) bright field images and (c, d) high resolution TEM image with FFT as the inset, and (e, f) dark fielding images of HG1 at the tab section.

Figure 18 shows the microstructure of the HG1 at the gauge section. Precipitates are accumulated at grain boundaries, as shown in Figure 18a. The bright precipitates are TiC particles (pointed by the red arrows), and the dark particles are the $\mathrm{M}_{23} \mathrm{C}_{6}$ precipitates (pointed by the blue arrowss). Unlike the G92-2b samples tested at room temperature, the tensile test of $\mathrm{HG} 1$ was conducted at its irradiation temperature of $580^{\circ} \mathrm{C}$. It is unclear if the "perfect" alternating alignment of $\mathrm{TiC}$ and $\mathrm{M}_{23} \mathrm{C}_{6}$ precipitates at the grain boundary was facilitated by boundary migration during the $580^{\circ} \mathrm{C}$ tensile test. Figure $18 \mathrm{~b}$ shows the diffraction patterns of matrix under [001] zone. The secondary diffraction spots are from the $\gamma^{\prime}$ precipitates. This shows that the $\gamma^{\prime}$ precipitates have the cube-on-cube orientation relationship with the matrix. Figure $18 \mathrm{c}$ shows the dark field image of $\gamma^{\prime}$ precipitates, which has sizes of about $10 \mathrm{~nm}$.
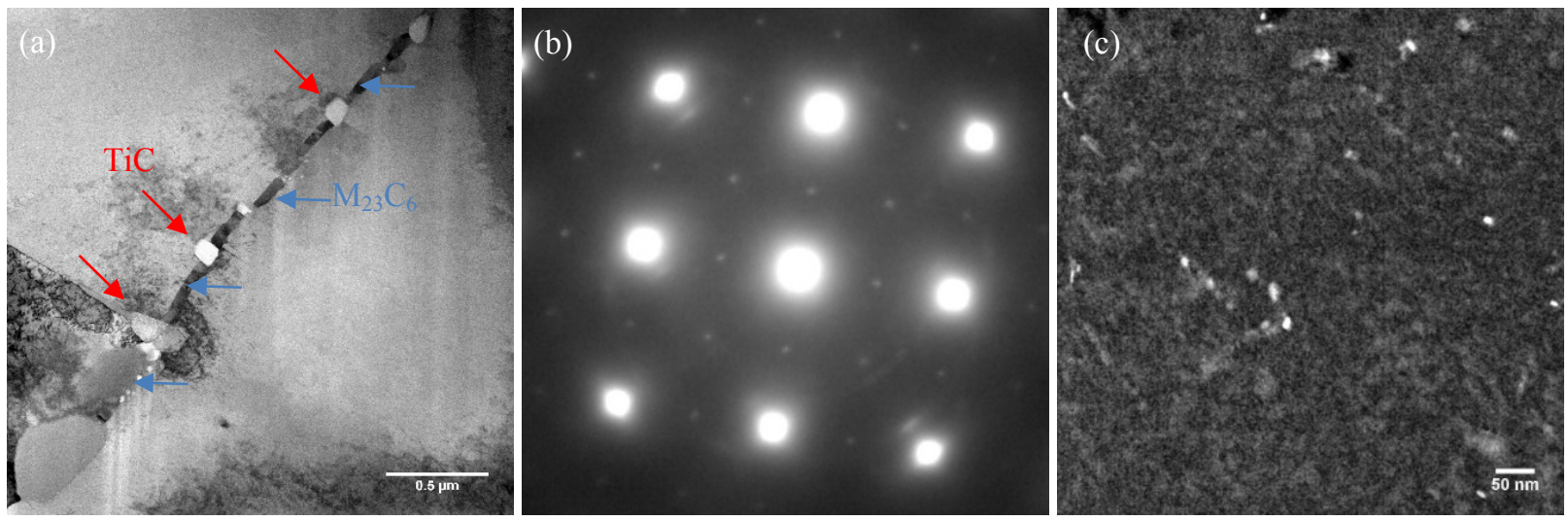

Figure 18. STEM (a) bright field image and (b) diffraction pattern under [001] zone and (c) dark field image of $\gamma$ ' precipitates of $\mathrm{HG1}$ at the gauge section. 


\subsubsection{T91 - TA\#1c (unirradiated)}

Microstructure of the unirradiated T91 was characterized, as the result shown in the Figure 19. Figure 19a shows the overall image of the TA\#1c. $\mathrm{M}_{23} \mathrm{C}_{6}$ precipitates decorate grain boundaries, as pointed in the Figure 19a. The size of $\mathrm{M}_{23} \mathrm{C}_{6}$ precipitates were quantified using $\sqrt{L W}$, where $L$ and $W$ are the length and the width of precipitates. The average size of the precipitates is $68 \pm 22 \mathrm{~nm}$. Nanoscale MX precipitates are present, as shown in the dark field image in Figure 19b. The image was taken under the two-beam condition $\mathrm{g}_{200}$ near [001] zone, as the diffraction pattern shown in the subset in the Figure 19b. The dislocation network is shown in STEM bright field image in Figure 19c that was taken under [001] zone.
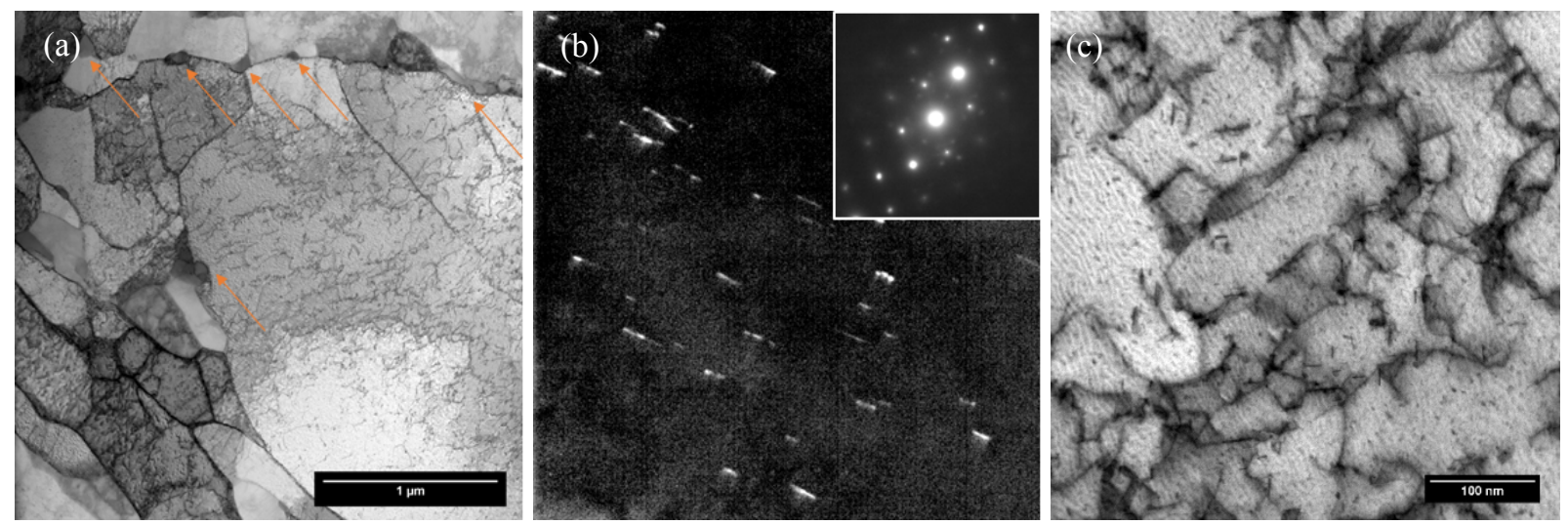

Figure 19. STEM (a, c) bright field image and (b) dark field image of MX precipitates of TA\#1c.

\subsubsection{T91 - TA04 $\left(6.5 \mathrm{dpa}, 295^{\circ} \mathrm{C}\right)$}

The microstructure of the TA04 after irradiation is shown in Figure 20. Figure 20a shows the STEM bright field image demonstrating the $\mathrm{M}_{23} \mathrm{C}_{6}$ precipitates. The average size of $\mathrm{M}_{23} \mathrm{C}_{6}$ precipitates was estimated to be $101 \pm 40 \mathrm{~nm}$, which is $48.5 \%$ increase in size compared to the reference TA\#1c. $\mathrm{M}_{23} \mathrm{C}_{6}$ precipitates are accumulated at grain boundaries. Figure $20 \mathrm{~b}$ shows the region as labeled in the dashed box in Figure 20a. Smaller grains are observed within the regions where $\mathrm{M}_{23} \mathrm{C}_{6}$ precipitates are accumulated, indicating the pinning effect of $\mathrm{M}_{23} \mathrm{C}_{6}$ precipitates on the grain growth. Dislocation loops formed in the irradiation environment, as shown in the STEM bright field image under [100] zone in Figure 20c. Both $\{111\}$ and $\{100\}$ type dislocations were observed.
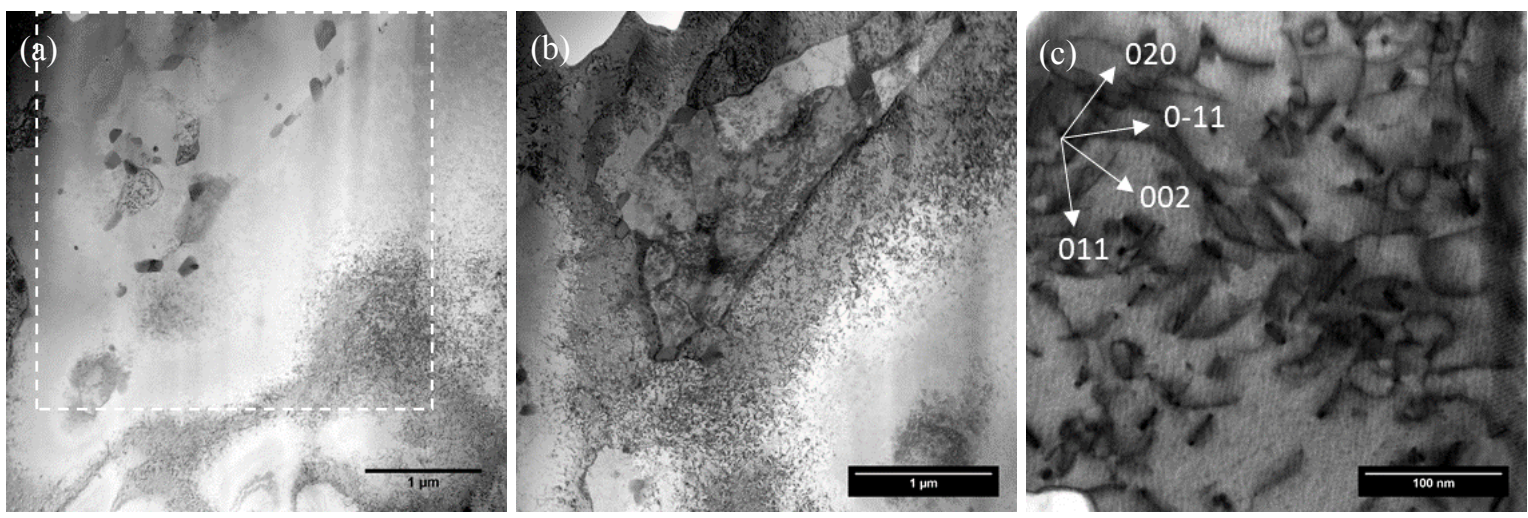

Figure 20. STEM bright field images showing $(a, b) M_{23} C_{6}$ precipitates and (c) dislocation loops at TA04. 


\section{CONCLUSION}

Selected samples of ferritic-martensitic steel G92-2b (an optimized Grade 92 heat) and austenitic stainless steel $800 \mathrm{H}$ and its Grain Boundary Engineering (GBE)-treated version 800H-TMP (ThermoMechanical Processing) were irradiated in the HFIR. Selected ferritic-martensitic steel T91 was irradiated in the ATR. The G92-2b samples were irradiated up to $14.66 \mathrm{dpa}$ at two temperature ranges: $400-496.7^{\circ} \mathrm{C}$ and $683.3-$ $720^{\circ} \mathrm{C}$. The $800 \mathrm{H}$ and $800 \mathrm{H}$-TMP samples were irradiated to $1.28 \mathrm{dpa}$ at $580^{\circ} \mathrm{C}$. The T91 sample was irradiated to $6.5 \mathrm{dpa}$ at $295^{\circ} \mathrm{C}$. Vickers hardness measurements, fractography, and microstructural characterization were performed in LAMDA.

Hardening of G92-2b was observed only at the lower doses and lower irradiation temperatures (400$\left.496.7^{\circ} \mathrm{C}\right)$, with GB03 $\left(0.52 \mathrm{dpa}\right.$ at $\left.400^{\circ} \mathrm{C}\right)$ and GB04 $\left(7.44 \mathrm{dpa}\right.$ at $\left.\sim 460^{\circ} \mathrm{C}\right)$ showing $\sim 12 \%$ and $\sim 8 \%$ hardening, respectively. Softening by $\sim 14 \%$ was observed for GB05 $\left(14.66 \mathrm{dpa}\right.$ at $\left.496.7^{\circ} \mathrm{C}\right)$ due to the longer irradiation time at $496.7^{\circ} \mathrm{C}$. Softening of $\mathrm{G} 92-2 \mathrm{~b}$ was more prevalent at the higher irradiation temperatures $\left(683.3-720^{\circ} \mathrm{C}\right)$, with GB10 $\left(0.46 \mathrm{dpa}\right.$ at $\left.683.3^{\circ} \mathrm{C}\right)$, GB11 $\left(7.44 \mathrm{dpa}\right.$ at $\left.\sim 720^{\circ} \mathrm{C}\right)$, and $\mathrm{GB} 12$ (14.63 dpa at $\sim 720^{\circ} \mathrm{C}$ ) showing $\sim 8 \%, \sim 8 \%$, and $\sim 40 \%$ softening, respectively. Samples AR2 (800H) and HG1 (800H-TMP) showed increased hardness after irradiation to 1.28 dpa at $580^{\circ} \mathrm{C}$. The lowtemperature-irradiated T91 (TA04 to $6.5 \mathrm{dpa}$ at $295^{\circ} \mathrm{C}$ ) shows $\sim 65 \%$ hardness increase, as compared to that of unirradiated T91 from the published literatures.

The fractography results of GB03 $\left(0.52 \mathrm{dpa}\right.$ at $\left.400^{\circ} \mathrm{C}\right), \mathrm{GB} 10\left(0.46 \mathrm{dpa}\right.$ at $\left.683.3^{\circ} \mathrm{C}\right)$, and $\mathrm{GB} 11(7.44 \mathrm{dpa}$ at $\sim 720^{\circ} \mathrm{C}$ ), together with the previously completed fractography of GB04 (7.44 dpa at $\left.\sim 490^{\circ} \mathrm{C}\right)$, GB05 (14.66 dpa at $496.7^{\circ} \mathrm{C}$ ), and GB12 $\left(14.63 \mathrm{dpa}\right.$ at $\left.\sim 720^{\circ} \mathrm{C}\right)$, indicated that the ductility of G92-2b was maintained up to $14.66 \mathrm{dpa}$ at the lower irradiation temperatures of $400-496.7^{\circ} \mathrm{C}$, while some loss of ductility (less necking) was observed for higher doses at the higher irradiation temperatures of 683.3$720^{\circ} \mathrm{C}$. This is in an agreement with the previously reported tensile tests results of $\mathrm{G} 92-2 \mathrm{~b}$, where the elongation of G92-2b was reduced at higher doses. Dimple sizes increased at higher doses, which are more evident at the higher irradiation temperatures of $683.3-\sim 720^{\circ} \mathrm{C}$. Fractography of $800 \mathrm{H}$ and $800 \mathrm{H}-$ TMP suggests that both samples failed in a brittle mode by intergranular fracture with negligible necking.

EBSD characterization of GB12 $\left(14.63 \mathrm{dpa}\right.$ at $\left.\sim 720^{\circ} \mathrm{C}\right)$ showed the recovery of lath structure, which was generally replaced by an equiaxed grain structure. TEM characterization showed the presence of $\mathrm{M}_{23} \mathrm{C}_{6}$ $(\mathrm{M}=$ primarily $\mathrm{Cr}), \mathrm{MX}(\mathrm{M}=$ primarily $\mathrm{V})$, spherical $\mathrm{NbN}$ precipitates, and Laves phase precipitates in the G92-2b samples. MX precipitates with sizes of 20-30 nm were observed at boundaries of smaller grains, indicating the pinning effect of $\mathrm{V}$-rich precipitates. Lath structure recovery was more evident at the higher irradiation temperatures $\left(683.3-\sim 720^{\circ} \mathrm{C}\right)$. The densities of line dislocations and of $\mathrm{M}_{23} \mathrm{C}_{6}$ precipitates decreased after irradiation. The irradiated T91 (TA04) showed the growth of $\mathrm{M}_{23} \mathrm{C}_{6}$ precipitates from $68 \pm 22 \mathrm{~nm}$ to $101 \pm 40 \mathrm{~nm}$ after irradiation. Dislocation loops of both $\{100\}$ and $\{111\}$ types were present in TA04. AR2 $(800 \mathrm{H})$ showed accumulation of large $\mathrm{M}_{23} \mathrm{C}_{6}$ precipitates at grain boundaries. Many smaller $\mathrm{M}_{23} \mathrm{C}_{6}$ precipitates, having a cube-on-cube orientation relationship with the matrix, were observed inside grains. Accumulation of large $\mathrm{M}_{23} \mathrm{C}_{6}$ and TiC precipitates was observed at grain boundaries in sample HG1 $(800 \mathrm{H}-\mathrm{TMP})$. Fine $\mathrm{M}_{23} \mathrm{C}_{6}$ and $\mathrm{TiC}$ precipitates were also present inside grains with TiC often embedded in the $\mathrm{M}_{23} \mathrm{C}_{6}$ precipitates. $\gamma$ ' precipitates were observed inside grains of both AR2 and HG1 samples, which have a cube-on-cube orientation relationship with the matrix.

Further systematic data analyses, together with some complementary experiments, will be pursued for these samples to foster peer-reviewed journal article publications. 


\section{REFERENCES}

[1] L. Tan, "Partial completion of post-irradiation examination of the ORNL samples (No. ORNL/TM2019/1135)," Oak Ridge National Lab.(ORNL), Oak Ridge, TN (United States)., 2019.

[2] L. Tan, T. Chen, K. Linton, C. Knight and T. A. Saleh, "First annual progress report on the procurement and post-irradiation examination of the selected samples of alloy $800 \mathrm{H}$ and Grade 92 and 91 steels (No. ORNL/TM-2019/1136)," Oak Ridge National Lab.(ORNL), Oak Ridge, TN (United States)., 2019.

[3] L. Tan, P. J. Maziasz and T. L. Sham, "Report on the optimization and testing results of advanced ferritic/martensitic alloys. ORNL/TM-2012/288," 2012.

[4] L. Tan and T. Allen, "An electron backscattered diffraction study of grain boundary-engineered INCOLOY alloy 800H," Metallurgical and Materials Transactions A, vol. 36, no. 7, pp. 1921-1925, 2005.

[5] L. Tan, T. R. Allen and J. T. Busby, "Grain boundary engineering for structure materials of nuclear reactors," Journal of nuclear materials, vol. 441, no. 1-3, pp. 661-666, 2013.

[6] L. Tan, L. Rakotojaona, T. R. Allen, R. K. Nanstad and J. T. Busby, "Microstructure optimization of austenitic Alloy $800 \mathrm{H}$ (Fe-21Cr-32Ni)," Materials science and engineering: A, vol. 528, no. 6, pp. 2755-2761, 2011.

[7] L. Tan, K. Sridharan and T. R. Allen, "The effect of grain boundary engineering on the oxidation behavior of INCOLOY alloy $800 \mathrm{H}$ in supercritical water," Journal of Nuclear Materials, vol. 348, no. 3, pp. 263-271, 2006.

[8] L. Tan, K. Sridharan and T. R. Allen, "Altering corrosion response via grain boundary engineering," Materials Science Forum, vol. 595, pp. 409-418, 2008.

[9] L. Tan, K. Sridharan, T. R. Allen, R. K. Nanstad and D. A. McClintock, "Microstructure tailoring for property improvements by grain boundary engineering," Journal of Nuclear Materials, vol. 374, no. 1-2, pp. 270-280, 2008.

[10] L. Tan, T. Allen and Y. Yang, "Corrosion behavior of alloy $800 \mathrm{H}$ (Fe-21Cr-32Ni) in supercritical water," Corrosion Science, vol. 53, no. 2, pp. 703-711, 2011.

[11] R. K. Nanstad, D. A. McClintock, D. T. Hoelzer, L. Tan and T. R. Allen, "High temperature irradiation effects in selected Generation IV structural alloys," Journal of Nuclear Materials, vol. 392, no. 2, pp. 331-340, 2009.

[12] L. Tan, J. T. Busby, H. J. Chichester, K. Sridharan and T. R. Allen, "Thermomechanical treatment for improved neutron irradiation resistance of austenitic alloy (Fe-21Cr-32Ni)," Journal of Nuclear Materials, vol. 437, no. 1-3, pp. 70-74, 2013.

[13] L. Tan, K. Linton, C. Knight and T. A. Saleh, "Identification and shipment progress of the INL and LANL samples to be received at ORNL (No. ORNL/LTR-2019/1083)," Oak Ridge National Lab.(ORNL), Oak Ridge, TN (United States)., 2019.

[14] S. A. Maloy, T. A. Saleh, O. Anderoglu, T. J. Romero, G. R. Odette, T. Yamamoto, S. Li, J. I. Cole and R. Fielding, "Characterization and comparative analysis of the tensile properties of five tempered martensitic steels and an oxide dispersion strengthened ferritic alloy irradiated at $\approx 295^{\circ} \mathrm{C}$ to $\approx 6.5$ dpa," Journal of Nuclear Materials, vol. 468, pp. 232-239, 2016.

[15] G. Gupta, Z. Jiao, A. Ham, J. Busby and G. Was, "Microstructural evolution of proton irradiated T91," Journal of Nuclear Materials, vol. 351, pp. 162-173, 2006. 